\title{
Ortaokul Öğrencilerinin Müzik Öğretmenine İlişkin Metaforik Algıları
}

Fatıma AKYÜZLÜER*

- Geliş Tarihi: 25.12.2020 • Kabul Tarihi: 22.01.2021 • Çevrimiçi Yayın Tarihi: 26.01.2021

\section{$\ddot{\mathbf{O} z}$}

Bu çalışmanın amacı, ortaokul 6-7-8. sınıf öğrencilerinin müzik öğretmenlerini nasıl gördüklerine ilişkin görüş ve düşüncelerini metaforlar yardımıyla belirlemektir. Araştırma nitel yöntemle yapılmış, müzik öğretmenlerini metaforlar aracılığı ile betimlemeyi amaçlayan bir çalışmadır. Araştırmaya katılan öğrencilerden, müzik öğretmenlerini neye benzettiklerini ortaya çıkarmak amacıyla "müzik öğretmenim ... gibidir; çünkü ...", kalıbını tamamlamaları istenmiştir. Çalışmada veriler içerik analizi tekniği ile analiz edilmiştir. Çalışmada, Ağrı, Balıkesir, Batman, Çanakkale, Antalya, Denizli, Diyarbakır, Gaziantep, İstanbul, Kocaeli, Malatya illerindeki ortaokullarda 5., 6. ve 7. sınıflarda öğrenim gören 1463 öğrenciden veri toplanmıştır. Araştırma sonunda öğrenciler, "aile, yol gösterici, müzik terimi, müzik insanı, enstrüman, gökyüzü, doğa, duygu, canlılar” olmak üzere 9 temada çok sayıda metafor üretmişlerdir. Metaforların doğa-canlılar, öğretmenlik mesleği ve müzikle ilgili terimlerde toplandığı söylenebilir. Ortaokul öğrencileri müzik öğretmenlerine ilişkin olumlu duygular içerisindedir, müzik derslerinin haftalık ders saatinin arttırılması öğrencilerin okullara daha istekli gitmelerine yol açacağından önerilebilir.

Anahtar sözcükler: müzik öğretmeni, metafor, ortaokul öğrencileri, benzetme, mecaz

\section{Atıf:}

Akyüzlüer, F. (2021). Ortaokul Öğrencilerinin müzik öğretmenine ilişkin metaforik algılar1. Pamukkale Üniversitesi Eğitim Fakültesi Dergisi, 53, 60-86.doi:10.9779.pauefd.846801

\footnotetext{
* Doç.Dr., Pamukkale Üniversitesi Eğitim Fakültesi, Doi: 0000-0002-5271-0704, fatmayuz@pau.edu.tr
} 


\section{Giriş}

Öğretmeni ve öğretmenlik mesleğini tanımaya ve anlamaya çalışan araştırmaların sayısı gün geçtikçe artmaktadır. Araştırmacılar öğretmenlerin kişilik özelliklerinden mesleki özelliklerine kadar pek çok konuda araştırma yapmaktadır. Son on y1lda öğretmeni metaforlar aracılığı ile tanımlamaya çalışan çalışmalar da oldukça artmıştır. Öğretmen kavramı üzerine yapılan metafor çalışmalarının meta sentezinin yapıldığı bir çalımada 13 yüksek lisans tezi ve 38 makaleye ulaşılmıştır (Yıldızlı, Erdol, Baştuğ ve Bayram 2018). Çalışmanın kapsamı dışında tutulan diğer indekslerde yayınlanan pek çok çalışma düşünüldüğünde sayının artacağı söylenebilir.

Türk Dil Kurumu Büyük Türkçe Sözlük’te (2020), metafor kelimesi mecaz kelimesiyle eş anlamlı olarak gösterilmektedir. Mecaz kelimesi, gerçek anlamından başka anlamda kullanma, metafor olarak açıklanmaktadır. Öğretmen kavramının metaforlar yoluyla ortaya konulması ülkelerin eğitim sistemlerinde öğretmenlerin nasıl algılandığına ilişkin önemli bilgiler sunabilir (Yıldızlı ve Ark., 2018).

Metafor; bir şeyi veya bir fikri ona çok benzer niteliklere sahip başka bir şey ile genelde "gibi”, "benzer" sözcüklerini kullanmaksızın istenen tanımlamayı yapmak, anlatıma üslup güzelliği ve kolaylığı katmak anlamına gelmektedir. Başka bir deyişle metafor; bir kavramı, kelimeyi, terimi, olguyu daha güzel anlatmak amacı ile farklı bir kavramla betimleme sanatıdır (Aydın, 2006). Metaforlar, genellikle söylemi süslemeye yönelik söz sanatından ibaret sanılmaktadır ancak önemi bundan çok daha fazladır. Metafor kullanımı, genel olarak dünyayı kavrayışımıza yardım eden bir görme ve düşünme biçimi anlamına gelmektedir. "Metaforlar, insanların dünyayı nasıl algıladıklarına ilişkin açık ifadelerdir” (Kemal, 2003, s. $1)$.

Farklı alanlarda yapılan çalışmalar metaforun düşünme biçimi, dil ve bilim üzerinde olduğu kadar insanın kendini ifade edişi üzerinde de etki sahibi olduğunu göstermektedir (Morgan, 1986). Metaforların olayların oluşumu ve işleyişi hakkında düşünceleri yapılandıran, yönlendiren ve kontrol eden en güçlü zihinsel araçlardan birisi olduğu düşünülmektedir.

Metaforlar üzerine 1980'li yıllardan günümüze farklı disiplinlerde birçok çalışma yapılmıştır. Bu çalışmalar metaforların bireyde yarattığı etkileri gösterir. Metafor bireyde bilişsel ve duyuşsal etkiler yaratır. Bilişsel ve duyuşsal süreçlerin etkileşimi bireyin hem kendisinin hem de karşısındakinin duygu ve düşüncelerini tanımlarken aynı zamanda 
metaforlardan yararlanmasına yol açar. Bu bağlamda metaforlar bireylerin hem yaratıcı düşünme ve hayal etme biçimlerini hem de dünyayı ve kendilerini algılama biçimlerini gösterir (Girmen, 2007). Metaforlar öğrenmeyi geliştirmek için son derece önemlidir. Eğer ki yeni bir şeyler keşfedilmek isteniyorsa öncelikle bunun hayal edebilebilmesi gerekir. Aynı zamanda metaforlar, belirsiz bir kavramdan ziyade açık ve net düşünceler inşa etmekte ve sezgisel değerlere sahip çıkmaktadır (Çelikkaya ve Seyhan, 2017).

Metaforlar eğitimin çeşitli alanlarında kullanılabilmektedir. Eğitim alanında metaforlara müfredat geliştirme ve planlamada; öğretim alanında da öğrenmeyi teşvik etme ve yaratıcı düşünceyi geliştirmede başvurulmaktadır. Öğretmen eğitiminde ise metaforlar, öğretim uygulamalarını yönlendirmede ve öğretmenlerin modern eğitim anlayışındaki yerlerini belirlemede bir araç konumundadır (Vadebocoeur ve Torres'ten akt. Arslan ve Bayrakc1, 2006).

Öğretmen adaylarının oluşturdukları metaforlar, öğretim sürecindeki rollerini ve öğrencileri nasıl gördüklerine ilişkin düşünce, inanç ve tutumlarının anlaşılmasını sağlayabilir. Metafor analizleri, öğretmen eğitimcilerin, öğretmen adaylarını tanımalarına ve onlara yol göstermesine yardımcı olabilir. Metaforların öğretmen adaylarının sorunlarının kaynağına ilişkin ipuçları verebileceği ve yansıtıcı düşünmeyi sağlayabileceği belirtilmelidir (Marshall, 2001).

Müzik öğretimi- en geniş anlamda- müzik öğretmenlerinin hem resmi hem de gayrı resmi ortamlar da dahil olmak üzere birden fazla öğrenme bağlamında müzik öğretme, mesleki bilgi ve becerilerini kullanan uygulama alanı ve özel bir disiplin olarak kabul edilse de, genellikle sıkı kuralara bağlı, bilimsel ve standartlaştırılmış profesyonel özelliklere sahip bir meslek olarak görülmez (Comte 1988; Russell-Bowie ve ark. 1995; Akt. Burnard 2016). Müzik öğretmenleri öğrencileriyle formal ilşkilerden daha çok informal olarak ilişki kurdukları söylenebilir. Müzik dersinin özelliği gereği, öğrencileriyle ders dışında çeşitli çalışma ve gösteriler için bir araya gelirler.

Müzik öğretmenliği kendine özgü bir meslektir. Müzik öğretmenliği eğitimi, bu mesleğe yönelen veya yöneltilen bireyleri müzik alanında öğretmenleştirme sürecidir (Uçan, 2006). Müzik öğretmeni yaşadığı toplumsal ve kültürel çevrede sanat ve müzikle ilgili yanlış inanç ve değerleri ortadan kaldıracak bilinçte ve güçte olmalıdır. Öğretmen, öğrencilere yerel, ulusal ve evrensel müziğin ne olduğunu kavratarak onların bu konudaki çelişkilerini ortadan kaldırmalı ve bilinç düzeylerini yükseltmelidir. Çevrede, ülkede ve dünyada müzikle 
ilgili meydana gelen gelişmeleri takip ederek bunun farkında olmalı ve öğrencilerle bunu paylaşmalıdır (Akbulut, 2006).

İyi bir müzik öğretmeninin genel kültür, konu alan bilgisi ve öğretmenlik meslek bilgisine ve birtakım kişisel yeterliklere de sahip olması gerekmektedir. Öğretmenlik Mesleği Genel Yeterlikleri belgesinde öğretmenlerin kazanması gereken yeterlilikler; mesleki bilgi, mesleki beceri, değer ve tutumlar ana başlığında sıralanmıştır (MEB, 2017). $\mathrm{Bu}$ yeterlikler hizmet öncesi programlar açısından belirleyici olabilir. Ancak meslek içerisinde, mesleğini nasıl icra ettikleri, hangi özelliklerinin öne çıktığı ve öğrenciler tarafından nasıl betimlendiklerinin bilinmesine ihtiyaç vardır. Öğrencilerin gözünden öğretmenleri değerlendiren çalışmalar hem öğretmen yeterliklerinin geliştirilmesine hem de öğretmenlerin kendilerinin gelişimleri sağlamalarına önemli katkılar sunabilir.

Türkiye'de eğitim alanında ve öğretmenlik mesleğiyle ilgili yapılmış katılımcısı farklı gruplar (öğrenci, öğretmen, öğretmen adayı, veli) olmak üzere pek çok metafor çalışması yapılmıştır. Bunlar örneklenecek olursa; Saban (2004), Aydın ve Pehlivan (2010), Çevik Kılıç (2017), öğretmen; Çelik, Çatalbaş, Tomul (2013), sınıf öğretmeni; Şahin (2013), matematik öğretmeni; Ahkemoğlu (2011) yabancı dil öğretmeni; Akça Berk, Gültekin, ve Çençen, (2015), sosyal bilgiler öğretmeni; Altun ve Camadan (2013), rehber öğretmen; Yalçın Wells (2015), görsel sanatlar öğretmeni; Karaşahinoğlu (2015) beden eğitimi öğretmeni; Soysal ve Afacan (2012), fen bilimleri öğretmeni; Dursun (2015), Bilişim teknolojileri öğretmeni; Giren ve Durak (2015), okul öncesi öğretmeni; Gedikli (2014), Türkçe öğretmeni; Sarıtaş ve Çelik (2013), sınıf kavramı metaforları ile ilgili çalışmalar yapmışlardır. Müzik öğretmeni ve ilgili kavramlarla yapılan çalışmalar sınırlıdır. Girgin (2019), çalgı eğitimi; Özaydın (2019), ses; Ahmethan ve Yiğit (2018) müzik öğretmeni metaforu; Tez (2016) aynı çalışma içersinde Müzik, Müzik Dersi ve Müzik Öğretmeni metaforlarını incellemiştir.

$\mathrm{Bu}$ çalışmada, müzik öğretmenlerinin ortaokul öğrencileri tarafından bir insan ve meslek elemanı olarak metaforlar aracılığıyla nasıl tanımlandıkları ve nasıl betimledikleri incelenmiştir.

\section{Yöntem}

Pek çok çalışmada, metafor çalışmaları nitel araştırma yöntemlerinden biri olan fenomenoloji (olgu bilim) desenine dayandırılmıştır. Ancak, Patton (2014), metaforların olgu bilim yöntemle desenlenmesinin deneyimleri semboller aracılığı ile ortaya konulması 
açısından işlevsel bulmakla birlikte olgu bilim deseninin metafor analizleri düzeyine indirgenmemesi gerektiğini belirtmektedir. $\mathrm{Bu}$ nedenle tek başına metafor çalışmalarının olgu bilim (fenomenoloji) deseni ile açıklanması yeterli olmayabilir, ancak olgu bilim çalışmalarındaki deneyimin bir boyutunu oluşturabilir (Yıldızlı, Erdol, Baştuğ, Bayram, 2018). Miller (1990) metaforların; nitel araştırmada çeşitleme (Triangulation) yaparken kullanılabileceğini ifade etmektedirler. Metafor analizleri bazı kaynaklarda nitel araştırmalar tarama yöntemi içinde, bazı kaynaklarda ise kendi başına bir araştırma yöntemi olarak ifade edilmektedir (Yıldızlı ve Ark., 2018). Açıklanan gerekçelerle bu çalışmada nitel araştırma yönteminde ve tarama modelinde desenlendiği kabul edilmiştir. Veriler içerik analizi tekniği ile analiz edilmiştir.

\section{Çalışma Grubu}

Bu çalışmada farklılıkları belirlemek için geniş çaplı durumları ve önemli ortak örüntüleri belirlemek amacıyla Maksimum Çeşitlilik Örneklemesi yöntemi kullanılmıştır (Baltacı, 2018; 246). Maksimum çeşitlilik yöntemi, incelenen olay veya olguyla ilişkili çok sayıda farklılığg kapsayan ana temaları keşfetmek ve tanımlamayı amaçlamaktadır (Neuman, 2014) Araştırmanın katılımcıları 2018-2019 eğitim-öğretim yılında ortaöğretim 6, 7 ve 8. sınıfta okumakta olan öğrencilerdir. Çalışma grubunun seçiminde öğrencilerin önceden müzik dersi almış olmaları ve müzik öğretmenine yönelik algılarının belirli düzeyde oluşmuş olması istenildiğinden 6, 7 ve 8. sınıflarla çalışılmıştır. Araştırma Ağrı, Balıkesir, Batman, Çanakkale, Antalya, Denizli, Diyarbakır, Gaziantep, İstanbul, Kocaeli, Malatya illerinden 1463 öğrencinin katılımıyla gerçekleştirilmiştir. Araştırmayı oluşturan 1463 öğrencinin 452'si 6. sınıf, 510'u 7. sınıf, 501'i ise 8. sınıf öğrencileridir. 6. sinıf öğrencilerinin 293'ü k1z, 159'u erkek, 7. sınıf öğrencilerinin 290'ı kız, 220'si erkek, 8. sınıf öğrencilerinin 298'i k1z, 203’ü erkek öğrencidir.

\section{Verilerin Toplanması}

Çalışma grubunun müzik öğretmeni kavramına yönelik ürettikleri metaforları belirlemek amacıyla bir adet form kullanılmıştır. Veriler, araştırmacının formu uygulamaya yönelik eğitim verdiği müzik öğretmenleri tarafından öğrencilerin sınıf ortamlarında toplanmıştır. Çalışma grubunundan müzik öğretmenim ........ gibidir; çünkü ........" cümlesini boşluktaki yerlere yazarak tamamlamaları istenmiştir. Katılımcıların müzik öğretmenini neye benzettikleri ve devamında neden benzettiklerini açıklamaları istenmiştir. Toplanan formlar araştırmanın veri kaynağını oluşturmuştur. 


\section{Verilerin Analizi}

$\mathrm{Bu}$ araştırmada verilerin analizi içerik analizi tekniği kullanılarak yapılmıştır. İçerik analizi, belli kurallar çerçevesindeki kodlamalarla bir metin olarak sunulan mesajdan tarafsızca çıkarımların yapıldığg üst ve alt kategoriler olarak ayrıştırılan sistematik bir tekniktir (Büyüköztürk, Çakmak ve Akgün, vd., 2009). İçerik analizindeki asıl amaç kavram ve ilişkilere ulaşıp toplanan verileri açıklamaktır. Toplanan veriler önce kavramsallaştırılır ve bu kavramlara göre organize edilerek temalar saptanır (Yıldırım ve Şimşek, 2005).

Kategori oluşturma çalışmaları sırası ile listeleme, eleme, kategori geliştirme, temaların oluşturulması, verilerin frekanslarının belirtilmesi, değerlendirme aşamalarında gerçekleştirilmiştir. Araştırma verileri ilk olarak üretilen metaforlar ve gerekçelerini temellendiren bir liste haline getirilmiştir. Ardından metaforla ilişkisi olmadığı düşünülen veri formları araştırmadan çıkarılmıştır. Araştırmacı tarafından toplanan 1610 formdan 147'si çıkarılarak 1463 form araştırmaya dahil edilmiştir. Araştırmaya dahil edilen veriler ifadelerin gerekçeleri de dikkate alınarak kodlanmıştır. Belirlenen 9 ana tema; aile, canlılar, doğa, duygu, enstrüman, gökyüzü, müzik insanı, müzik terimi, yol gösterici olarak isimlendirilmiş ve sıralarıyla bulgularda verilmiştir.

\section{Geçerlik ve Güvenirlik}

Araştırmanın geçerliği veriler analiz edilirken oluşturulan temaların anlamlı bir bütün oluşturmasına ve araştırma süreci ayrıntılı bir biçimde açıklanarak sağlanmaya çalışılmıştır. Araştırmanın güvenirliğini arttırmak amacı ile bulguların tamamı yoruma yer vermeksizin doğrudan verilmiştir. Aynı zamanda güvenirliği arttırmak için başka bir uzmandan görüş alınmıştır. Bu doğrultuda araştırmaya ilişskin metaforlar temalara ayrıldıktan sonra başka bir alan uzmanı tarafından metaforları verilen kategorilere yerleştirmesi istenmiştir. Araştırmada Miles ve Huberman’ın (1994) Güvenirlik = Görüş Birliği x 100 / Görüş Birliği + Görüş Ayrılığg güvenirlik formülü kullanılarak güvenirlik hesaplanmıştır. Sonuç olarak \%83 oranında görüş birliği olduğu belirlenmiştir. Tüm bu işlemler sonucunda çalışmanın geçerli ve güvenilir olduğu söylenebilir.

\section{Bulgular}

Toplanan verilerin analizi sonucunda "müzik öğretmeni" dokuz tema ve temalar içerisinde aşağıda gösterildiği şekilde çok sayıda metaforla ifade edilmiştir. Araştırmadan elde edilen temalar özet olarak şekil 1'de sunulmuş ve devamında temalar ve metaforlar tablolar halinde verilerek yorumlanmıştır. 


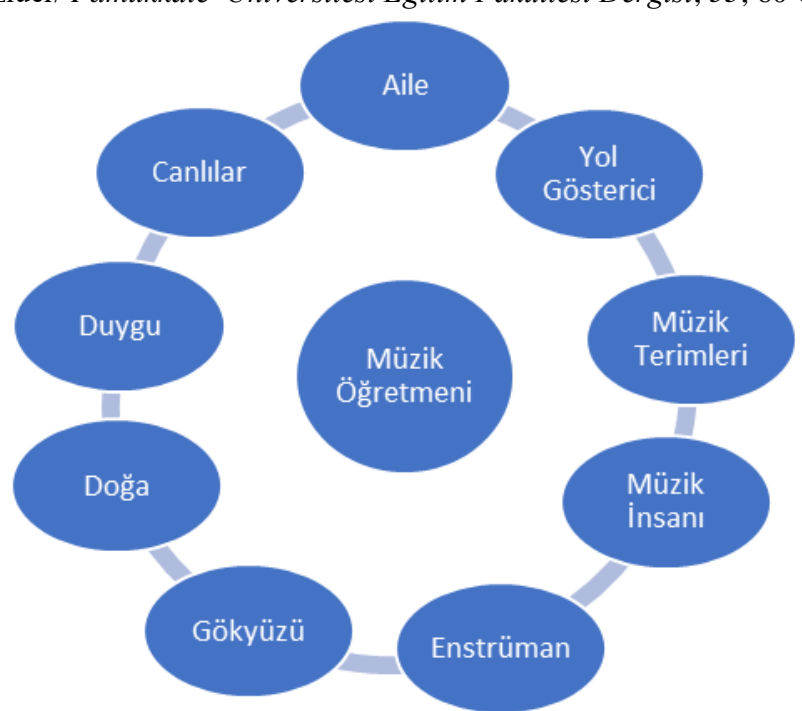

\section{Şekil 1. Müzik Öğretmeni Temaları}

Temalara ilişkin sonuçlar genel olarak değerlendirildiğinde; pek çok öğretmen metaforu çalışmasında ortak olarak görülen temaların bu çalışmada da görüldüğü, ayrıca müzik öğretmenliği mesleğine özgü yeni temaların da elde edildiği görülmektedir. Çok farklı gruplarla yapılan metafor analizlerinde öğretmenlerin benzer temalarla açıklanmaya çalış1ldığı görülmektedir. Öğretmen metaforlarının incelendiği bir meta analiz çalışmasında (Yıldızlı, Erdol, Baştuğ, Bayram, 2018); öğretmenlere yönelik üretilen metaforların; bilgi sağlayıcı, şekillendirici-biçimlendirici ve iyi bir insan adı verilen üç temada toplandiğ 1 vurgulanmıştır. Yapılan bu çalışmada, bazı temalar müzik öğretmenlerinin yaptıkları işe özgü olarak oluşmuştur. Müzik öğretmeni ile ilgili oluşturulan temaların ağırlıklı olarak duygu yükü ağır olan metaforlarla oluşması yapılan işin duygusal boyutunu yansıttığı şeklinde değerlendirilebilir.

Tablo 1'de öğrencilerin müzik öğretmenlerinin neye benzediğine ilişkin verdikleri yanıtlardan oluşturulan "aile" temasında üretilen metaforlar ve bu metaforlara ilişkin frekanslar görülmektedir.

$\mathrm{Bu}$ temada yer alan metaforlar incelendiğinde, öğrencilerin müzik öğretmenini, öğretmenlik rollerinden çok öğrencilerine yaklaşımı ve onlarla kurdukları iletişim biçimine göre betimledikleri görülmüştür. Bu ilişkinin temelinde, sevgi, sıcaklık, samimiyet duygusu ile öğrencilere kol kant germe davranışlarının yer aldığı görülebilir. Öğretmeni, annem, babam, abim, ablam gibi aile üyeleri kadar yakın hissedecek metaforlarla bu duygular belirtilmiştir. 


\begin{tabular}{|c|c|c|}
\hline Tema & Üretilen Metaforlar & $\mathrm{f}$ \\
\hline & Anne & 35 \\
\hline & Baba & 21 \\
\hline & Aile & 20 \\
\hline & Abi ve Abla & 9 \\
\hline \multicolumn{3}{|l|}{ Aile } \\
\hline & Anne ve Baba & 7 \\
\hline & Ebeveyn & 6 \\
\hline & Çocuk & 4 \\
\hline & Akraba, ev, kız kardeş & 1'er kez \\
\hline
\end{tabular}

Katılımcılar bu temada oluşan metaforkara ilişkin gerekçelerini; "anne gibi davranır, bizi çok sever, bizi korur, bizi sever, flüt çalmayı öğretir, her şeyi yapar, ışık verir, iyi davranır, merhametli, müziği sevdirir, okulu yuvaya çevirir, şefkatlidir, yeni şeyler öğretir, yol gösterir, bizle ilgilenir." şeklinde ifade etmişlerdir. Öğrencilerin ortaokul öğrencisi olduğu düşünüldüğünde öğretmenlerini ailelerinin bir üyesi gibi yakın görmek istedikleri söylenebilir. Özellikle metforların ağırlıklı olarak anne-baba, abi-abla ifadelerinde toplandığı görülmektedir. $\mathrm{Bu}$ durum öğrencilerin öğretmenleriyle yakın ilişki aradıkları şeklinde yorumlanabilir.

Tablo 2'de öğrencilerin müzik öğretmenlerinin neye benzediğine ilişkin verdikleri yanıtlardan oluşturulan "canlılar" temasında oluşan alt kategoriler ve bu kategorilerdeki frekanslar görülmektedir 


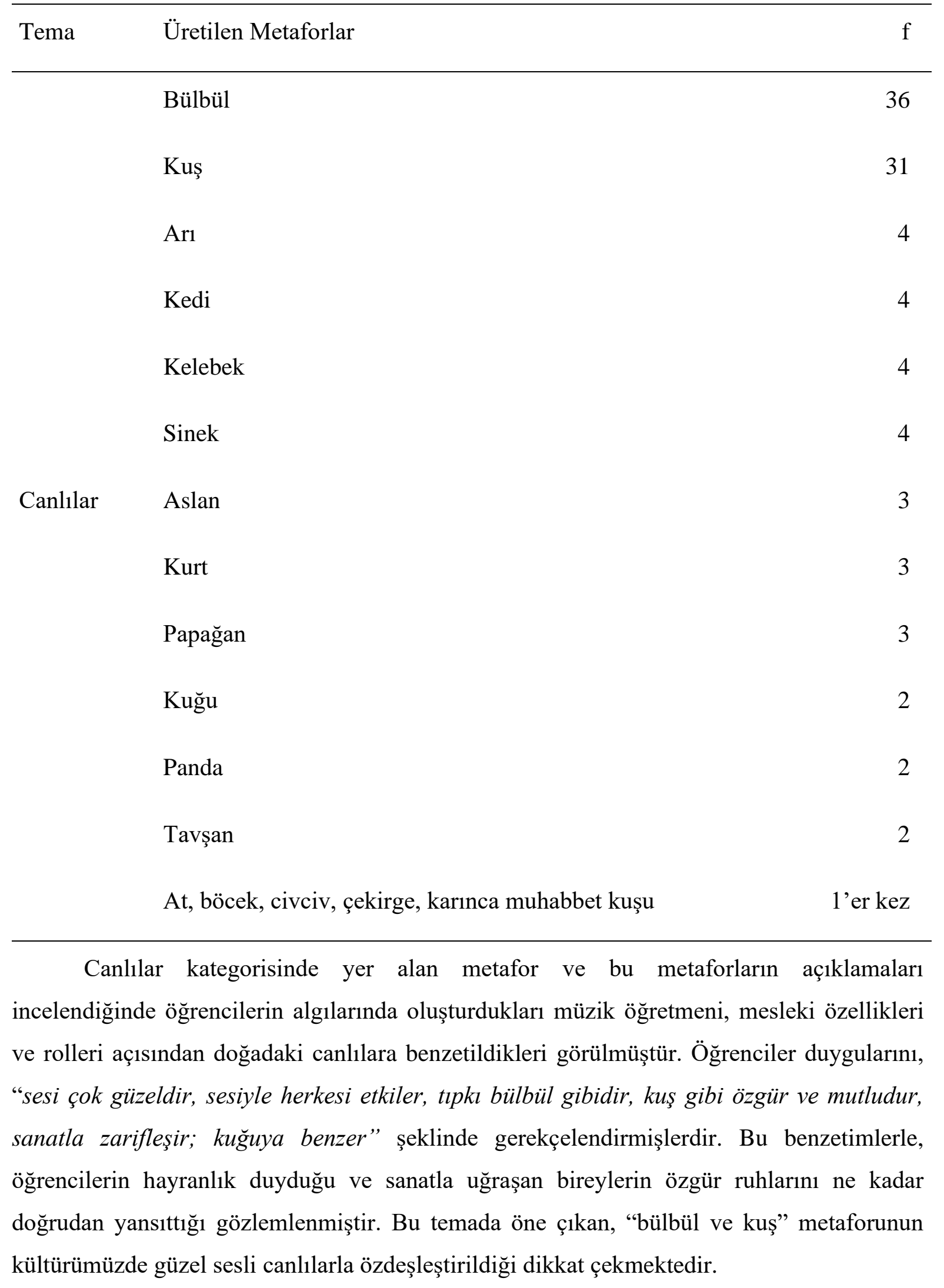


Tablo 3'te öğrencilerin müzik öğretmenlerinin neye benzediğine ilişkin verdikleri yanıtlardan oluşturulan "Doğa" temasında oluşan alt kategoriler ve bu kategorilerdeki frekanslar görülmektedir

Tablo 3. Doğa Teması Alt Kategorileri ve Frekanslart

\begin{tabular}{|c|c|c|}
\hline \multirow[t]{2}{*}{ Tema } & Üretilen Metaforlar & f \\
\hline & Çiçek & 131 \\
\hline & Gül & 38 \\
\hline & A ğaç & 15 \\
\hline & Papatya & 13 \\
\hline & Rüzgar & 8 \\
\hline & Bal & 3 \\
\hline & Orman & 3 \\
\hline & Bahar & 2 \\
\hline Doğa & Bitki & 2 \\
\hline & Elma & 2 \\
\hline & Göl & 2 \\
\hline & $\begin{array}{l}\text { Ayçiçeği, cennet, çilek, diken, dikenli gül, dikensiz gül, doğa, doğanın iç sesi, } \\
\text { kardelen, lale, meyve ağacı, nar, nehir, okyanus, portakal, yaprak, eğlence, hayat, } \\
\text { şeker, neşe, sevgi çiçeği, peri, can pamuk, dost, pamuk şekeri, boya, enerjik, } \\
\text { heyecan, huzur, neşe kaynağı, çikolata, gıda, kahraman, lunapark, palyaço, aşk } \\
\text { sözleri, deniz, dil, dolap, dondurma, duygu, emoji, esinti, film, filtre, güler } \\
\text { yüzlü, hoşgörü, inci tanesi, insan, iyilik perisi, kaymaklı kadayıf, lokum, makine, } \\
\text { mandalina, narin bir parça, narin bulut, nefes, pasta kreması, pırlanta, sabır taşı, } \\
\text { seratonin, ses dalgaları, sevilen yemek, sıcak hava, sihirli bir şarkı, soba, } \\
\text { solmayan gül, şelale, şirin, tablo, tahta, tarla, taş, yeni açmış gül, zehir }\end{array}$ & $\begin{array}{l}1 \text { 'e } \\
\mathrm{r} \\
\mathrm{kez}\end{array}$ \\
\hline
\end{tabular}


Doğa temasında öğretmenlerin çiçek, gül, ağaç, papatya, rüzgâr, orman vb. metaforlarında doğanın bir parçası ile müziğgi birleştiren bir anlayışla gördükleri söylenebilir. Tıpkı doğadaki diğer varlıklar gibi müziğin ruhlarımızı besleyip büyüttüğü bir anlayış sergilenmektedir. Öğrenciler, öğretmenlerine "çiçeğe benzer, çiçek gibi açar, çiçeklere dans ettirir, dallarl kopmaz, derinlere indikçe güzellikler bulursun, dikeni olduğu halde batmaz, en güzel varlıktır, estikçe bilgisi ile ferahlatır, gölgesinde toplar, güzel açmış çiçek gibidir, her müzikte yeniden açar, herkes gülü sever, herkese doğallıkla yaklaşır, ilkbaharda açar, mis kokular bırakır, orman kocaman bir yer ve farklı sesler çıkarıyor, ögrenciler onun yapraklarıdır, rengi ve asaletiyle bizi büyüler, rüzgar gibidir, yeni çiçekler üretir” gerekçeleriyle metaforlarını açıklamışlardır. Bu temada öne çıkan "çiçek ve gül" metaforunun güzellik ve sevgi ile ilişkilendirilebilir. Müzik öğretmenlerinin böyle bir atmosfer yaratabilmesi öğrenci öğretmen bağı için istenir bir durum olduğu söylenebilir.

Tablo 4'de öğrencilerin müzik öğretmenlerinin neye benzediğine ilişkin verdikleri yanıtlardan oluşturulan "Duygu" temasında oluşan alt kategoriler ve bu kategorilerdeki frekanslar görülmektedir

Tablo 4. Duygu Teması Alt Kategorileri ve Frekansları

\begin{tabular}{llr}
\hline Tema & Üretilen Metaforlar & $\mathrm{f}$ \\
\hline & Eğlence & 20 \\
& Hayat & 20 \\
& Şeker & 19 \\
& Neşe & 14 \\
Duygu & Sevgi Çiçeği & 14 \\
& Peri & 7 \\
Can & 5 \\
Pamuk & 5 \\
Dost & 5
\end{tabular}


Boya

Enerjik

Heyecan

Huzur

Neşe Kaynağ 1

Çikolata

Gida

Kahraman

Lunapark

Palyaço

Aşk sözleri, deniz, dil, dolap, dondurma, duygu, emoji, esinti, film, filtre, güler yüzlü, hoşgörü, inci tanesi, insan, iyilik perisi, kaymaklı kadayıf, lokum, makine, mandalina, narin bir parça, narin bulut, nefes, 1'er pasta kreması, pırlanta, sabır taşı, seratonin, ses dalgaları, sevilen kez yemek, sıcak hava, sihirli bir şarkı, soba, solmayan gül, şelale, şirin, tablo, tahta, tarla, taş, yeni açmış gül, zehir

Duygu temasında öğretmenlerin eğlence, heyet, şeker, neşe, sevgi çiçeği, peri, can, pamuk, metaforları öne çıkmaktadır. Öğrenciler bu metaforları "öğrenciye can veren, sesiyle canlılık ve mutluluk veren, eğlendiren, dersin mutlu ve keyifli geçmesini sağlayan, ruhu besleyen, hayata bağlayan, umutlandıran, sosyalleşmelerini sağlayan bir aracı” olarak gerekçelendirmektedirler. Müziğin duygularımıza hitap etmesi, öğrencilerin de derslerinde eğlenip hayata bağlanması bu derslerin amaçlarından biridir. $\mathrm{Bu}$ yönüyle müzik öğretmenlerinin derslerin amaçlarını gerçeleştirebildikleri söylenebilir. 
Tablo 5'te öğrencilerin müzik öğretmenlerinin neye benzediğine ilişkin verdikleri yanıtlardan oluşturulan "Enstrüman" temasında oluşan alt kategoriler ve bu kategorilerdeki frekanslar görülmektedir

Tablo 5. Enstrüman Teması Alt Kategorileri ve Frekanslart

\begin{tabular}{llr}
\hline Tema & Üretilen Metaforlar & $\mathrm{f}$ \\
\hline \multirow{2}{*}{ Enstrüman } & 24 \\
\cline { 2 - 3 } & Enstrüman/piyano & 11 \\
\cline { 2 - 3 } Enstrüman & Enstrüman/gitar & 8 \\
\cline { 2 - 3 } & Enstrüman/flüt & 6 \\
\cline { 2 - 3 } & Enstrüman/keman & 4 \\
\cline { 2 - 3 } & Enstrüman/bağlama & 3 \\
\cline { 2 - 3 } & Enstrüman/melodika & 2 \\
\cline { 2 - 3 } & Enstrüman/bateri, Enstrüman/davul, Enstrüman/saz & 1 'er kez \\
\hline
\end{tabular}

Enstrüman temasında öğretmenlerin kullanmış oldukları müzik aletleri ile öğretmenleri özdeşleştiren bazı benzetimler yapılmıştır. Bu benzetimlerde genel olarak enstrümandan söz edilirken öğretmenin kullandığı bazı müzik aletlerinin de öğretmenlerle ilişkilendirildiği görülmektedir. Buna ilişkin gerekçelendirmelerde "enstrüman gibi konuşur, her şeyi çalar, notaları birbirine bağlar, çalmamıza yardım eder, sesi tellerden gelir, sesiyle insanı hayran bırakır, telleri birleşince bir bütün oluşur, tellerle yakınlığı öğrencilerine bă̆lıdır, başka dünyalara götürür, birlikte uyumlu, müzikteki duyguları anlatır, piyano çalıyor, sesinde tüm notalar vardır, güzel ses çıkar" olarak gerekçelendirilmektedir.

Tablo 6'da öğrencilerin müzik öğretmenlerinin neye benzediğine ilişkin verdikleri yanıtlardan oluşturulan "Gökyüzü” temasında oluşan alt kategoriler ve bu kategorilerdeki frekanslar görülmektedir 


\begin{tabular}{llr}
\hline Tema & Üretilen Metaforlar & $\mathrm{f}$ \\
\hline Güneş & 88 \\
& Ay & 23 \\
& Yıldız & 21 \\
& Yağmur & 7 \\
Gökyüzü $\quad$ Bulut & 6 \\
& Gökyüzü & 4 \\
Gökkuşağı & 3 \\
Gündüz, ilkbahar, karadelik & 1 'er kez
\end{tabular}

Gökyüzü temasında öğrenciler öğretmenlerini güneş, ay, yıldız gibi parlayan gökyüzü cisimleriyle anlatma yolunu seçmişlerdir. $\mathrm{Bu}$ benzetimlerden bu gök cisimlerinin 1 ş1k saçması ve yansıtması gibi müzik öğretmenlerinin öğrencilerini aydınlatan, ışı saçan bir mesleğin elemanları olduğu söylenebilir. Aslında gökyüzü temasıyla müziğin evrenselliği, duygularda yarattığı sonsuzluk fikri açıkça görülebilmektedir. Bu temaya ilişkin öğrencilerin ifadeleri” Aydınlatır, parlatır, yolumuzu aydınlatır, ışıldar, geleceğimizi aydınlatır, bulut gibi soğuk güneş gibi slcak, görünce mutlu olur hayalleri hatırlarız, sonsuzdur, yıldız gibi dağıtır, dünyamızı aydınlatır, güneş gibi parlar, karanlı̆̆ aydınlatır, mutluluğuyla bizi aydınlatır, bizi kendi ışığıyla aydınlatır, geleceğimizi parlatır” şeklindedir.

Tablo 7'de öğrencilerin müzik öğretmenlerinin neye benzediğine ilişkin verdikleri yanıtlardan oluşturulan "Müzik İnsanı" temasında oluşan alt kategoriler ve bu kategorilerdeki frekanslar görülmektedir

Bu temada öğretmenler yoğunluklu olarak sanatçı ve şarkıcı olarak benzetilmiştir. $\mathrm{Bu}$ müzik öğretmenleri açısından beklenilen bir durumdur. Ayrıca bu temada, öğrenciler, öğretmenlerini bazı meslek elemanlarına benzetmişler ve isimlendirmişlerdir. Buradaki benzetimlerden öğretmenlerin iyileştirici, eğlendirici, duyguları aktarıcı, üretici ve usta yanları vurgulanmıştır. 
Tablo 7. Müzik Insanı Teması Alt Kategorileri ve Frekansları

\begin{tabular}{llr}
\hline Tema & Üretilen Metaforlar & f \\
\hline & Sanatçı & 74 \\
& Şarkıcı & 56 \\
& Doktor & 4 \\
& & \\
Müzik & Koro Şefi & 4 \\
İnsanı & Orkestra Şefi & 4 \\
& Komedyen & 3 \\
& Ressam & 3 \\
& Barış Manço, Çiftçi, Çoban, Hemşire, Heykeltıraş, İnşaat Çalışanı, & 1 'er \\
& Masalcı, Mimar, Piyanist, Senfoni, Sunucu, Şair, & kez \\
\hline
\end{tabular}

$\mathrm{Bu}$ temaya ilişkin öğrencilerin ifadeleri "müzikle iyileştirir, bizi şekillendirir, hayal gücümüzü inşa eder, müzikle insanı inşa eder, notalarla çizim yapar, notalarla çizim yapar, okur, sanatçıya dönüşür, sanatı ögreniriz, sanatı öğretir, huzur verir, moral verir, müzisyendir” şeklindedir. Bu temada müzik öğretmenliğinin icracı yönüne öğrenciler dikkat çekmişlerdir. Bu durum, müzik dersinin uygulamalı bir ders olmasından kaynaklanmaktadır.

Tablo 8'de öğrencilerin müzik öğretmenlerinin neye benzediğine ilişkin verdikleri yanıtlardan oluşturulan "Müzik Terimi" temasında oluşan alt kategoriler ve bu kategorilerdeki frekanslar görülmektedir 
Tablo 8. Müzik Terimi Teması Alt Kategorileri ve Frekansları

\begin{tabular}{llr}
\hline Tema & Üretilen Metaforlar & f \\
\hline & Nota & 79 \\
& Müzisyen & 15 \\
& Sol Anahtarı & 10 \\
& Melodi & 6 \\
Müzik & Ses & 5 \\
Terimi & Müzik Kitabı & 2 \\
& Müzik Kutusu & 2 \\
& Ritim & 2 \\
& Beste, müzik annesi, müzik deposu, müzik sözlüğü, nota kraliçesi, nota & 1 'er \\
& veren ağaç, , orkestra, pop star, porte, ses uyumu, türkü & kez \\
\hline
\end{tabular}

$\mathrm{Bu}$ temada öğretmenler yoğunluklu olarak nota, müzisyen, sol anahtarı olarak benzetilmişlerdir. Bu temada öğrenciler öğretmenlerini müzik terimi ile ilişkilendirmişlerdir. Bu temaya ilişkin öğrencilerin ifadeleri "notaları bilir, flüt çalmayı öğretir, her farklı nota gibi farklı düşüncelere sahiptir, müziği simgeler, müzik notalardan oluşur, müzik notaları ögretmen gibi, nota gibi güzeldir, nota gösterir, notalara ses verir, notalarl çok iyi bilir, notaları içimizde hissettirir, notaların içinden biri, notalarla arkadaş, notaya benzer, şarkı söylerken nota çıkarır, şarkı sözü gibidir, yükselir ve alçalır, hepimizi bir arada tutar, her sesi canlandırır, her şeyin başındadır, her notanın başında vardır" şeklindedir. Bu temada müzik öğretmenini müzik terimleri ile ilişkilendirilmiştir $\mathrm{Bu}$ ilişkilendirmenin derslerde kullanılan müzik terimlerinden kaynaklandığı düşünülmektedir.

Tablo 9'de öğrencilerin müzik öğretmenlerinin neye benzediğine ilişkin verdikleri yanıtlardan oluşturulan "Yol Gösterici" temasında oluşan alt kategoriler ve bu kategorilerdeki frekanslar görülmektedir 
Tablo 9. Yol Gösterici Temast Alt Kategorileri ve Frekansları

\begin{tabular}{|c|c|c|}
\hline Tema & Üretilen Metaforlar & $\mathrm{f}$ \\
\hline & Melek & 123 \\
\hline & Iş1k & 30 \\
\hline & $\mathrm{Su}$ & 25 \\
\hline & Mum & 15 \\
\hline & Kitap & 14 \\
\hline & Bilge & 9 \\
\hline & Arkadaş & 8 \\
\hline & Kraliçe & 8 \\
\hline & Anahtar & 6 \\
\hline Yol & Dünya & 5 \\
\hline \multicolumn{3}{|l|}{ Gösterici } \\
\hline & Kalem & 5 \\
\hline & Prenses & 5 \\
\hline & Fener & 4 \\
\hline & Rehber & 4 \\
\hline & Ruh Besleyici & 4 \\
\hline & Kandil & 3 \\
\hline & Psikolog & 3 \\
\hline & $\begin{array}{l}\text { Ak1l küpü, ateş, ayna , bayrak, elmas, kapı, kütüphane, lider, } \\
\text { öğretici, süper kahraman, yönetmen }\end{array}$ & $\begin{array}{l}2 \text { 'şer } \\
\text { kez }\end{array}$ \\
\hline & Altın, ansiklopedi, avcı, baş tacıdır, beyin, çilingir, dalga sesi, & 1 'er \\
\hline
\end{tabular}


havai fişek, ilham, kaynağı, kutup yıldızı, lamba, meşale, öğüt veren, özgür kuş, özgürlük, özgürlük perisi, parıltı, parlak, parlak yıldız, parlayan güneş, prens, profesör, pusula, saat, seyahat, spor koçu, tren, uçan balon, uçan kuş, usta, yazar, yeşillik, yoga öğretmeni, yönetici

$\mathrm{Bu}$ temada öğretmenler yoğunluklu olarak melek, 1şık, su, mum olarak benzetilmişlerdir. Bu temada öğrenciler öğretmenlerini, yol gösterici olarak görmüşlerdir. Bu temada öğrenciler, öğretmenlerini “Bilgilidir, hep öğretir, başka dünyaların kapısını açar, bilinçlidir, geleceğe açan kapıdır, zor kapıları açar, derdini anlattı̆̆ında derman bulursun, iyiliğimizi düşünür, melek gibi davranır, bizi korur ve sever, her şeyi görür, gülümsersen gülümser, karanlık günlerden bir eser, sesinde dalga vardır, aklımızı okur, bilmediklerimiz bilir, denizdeki dalgalar müzik yaparlar, su birikintisi oluşturur, sır müziğe dökülür, müzikle ilgili her şeyi bilir, benliğimizi hissettirir, müzikleri ve notalar fetheder, hayal ettiğim her şey var, geleceğe ışık tutar, geleceği gösterir, gittiğimiz yolu aydınlatır, karanlı̆̆a ışık tutar, kendini tüketir bize ışık verir, dışını beğenmezsin ama içi çok ĕglencelidir, farklı yetenek ve becerileri var, kelimelerle anlamlanır, okudukça okuyası gelir, en güzel ögretici, dersi yönetir, müziği öğretir, orduyu yönetir, yol gösterir, bütün bilgiler vardır, ayrımcılık yapmaz, derste melek gibi rahatlarsın, güzelleştirir, hayat gibi, hayata bağlar, iyi kalplidir, iyiliğimizi düşünür, kanatları vardır, melek gibi yüzü var, merhametli, ona güvenebilirsin, özeldir, kanatları var, müzik meleğidir, aydınlatırken erir, etrafindakilere ışık saçar, kilitli kapının arkasına götürür, geleceğe açılan kapı, seslerin prensesidir, ruhumuzdaki duyguyu anlar, sorunları çözer, yönlendirme yapar, bizim hissettiğimizi anlar, hayata bağlar, aktı̆̆ yere bizi götürür, çok saf ve berrak, rahatlarsın, su gibi anlatır, kanatları vardır, etkileyici sunum yapar, müziğin akışını kontrol eder" ifadeleriyle gerekçelerini ortaya koymuşlardır. Öğrenciler, bu benzetimleriyle öğretmenlerinin liderlik rolünü vurgu yaptıkları söylenebilir.

\section{Tartışma ve Sonuç}

Ortaokul öğrencilerinin öğretmenlerini neye benzettiklerini belirlemeye yönelik bu çalışmada 9 temada çok sayıda metafor üretilmiştir. Ortaokul öğrencileri, müzik öğretmenleriyle ilgili olumsuz hiçbir metafor üretmemiştir. Müzik dersi ve müzik öğretmenine olan ilgi çalışma boyunca sıklıkla vurgulanmıştır. “Aile”, "Yol Gösterici”, 
“Müzik Terimi”, “Müzik İnsanı”, “Enstrüman”, “Gökyüzü”, "Doğa”, “Duygu”, "Canlılar” olarak isimlendirilen temalarda çok sayıda metafor üretilmiştir.

Müzik öğretmeni kavramına ilişkin Tez (2016) tarafından yapılan çalışmada metaforlar "seven, güven veren ve koruyan”, "sanatçı", “bilgi kaynağı”, "hayranlık duyulan” kategorilerinde toplanmıştır. Tez'in çalışmasındaki kaegorilerin bu çalışma ile benzerlik taşıdığı söylenebilir. Ahmethan ve Yiğit (2018), müzik öğretmen adaylarının, ideallerindeki müzik öğretmenini metaforlar aracılığı ile belirledikleri çalışmalarında, "sevecen ve destekleyici öğretmen”, “bilgi aktaran öğretmen”, “yetenekleri ortaya çıkaran ve yönlendiren öğretmen”, “dikkat çeken öğretmen”, “eğlenceli öğretmen”, “terapist öğretmen”, “motivasyonu yüksek öğretmen”, “otoriter öğretmen” ve "adaletli öğretmen” olarak algıladıkları görülmüştür.

$\mathrm{Bu}$ çalışmada üretilen 9 temanın metaforlarını genel olarak değerlenrirecek olursak aşağıdaki sonuçlara ulaşılmaktadır. Aile temasında ortaokul öğrencilerinin öğretmenlerini anne-baba, abi-abla gibi aileden biri kadar yakın gördükleri söylenebilir. Duygu temasında ortaokul öğrencilerinin öğretmenlerini eğlence, hayat, şeker, neşe gibi kendilerini psikolojik olarak olumlu duygularla bezedikleri görülmektedir. Canlılar temasında ortaokul öğrencilerinin öğretmenlerini bülbül, kuş gibi sesleri çok güzel olan canlılara benzettikleri görülmektedir. Doğa temasında ortaokul öğrencilerinin öğretmenlerini çiçek, gül, ağaç gibi doğaya hayat veren nefes almasını sağlayan en hayati fonksiyonumuzdan bir olarak nitelemişlerdir. Gökyüzü temasında ortaokul öğrencilerinin öğretmenlerini güneş, ay, yıldız gibi gökyüzünü aydınlatan, yol gösteren, 1şık saçan cisimlere benzetmişlerdir. Enstrüman temasında ortaokul öğrencilerinin öğretmenlerini enstrüman, piyano, gitar sesi, tınısı insana kendisini hoş hissettiren enstrümanlarla tanımlamışlardır. Müzik İnsanı temasında ise ortaokul öğrencileri öğretmenlerini sanatçı, şarkıcı, gibi müzik yaşantısında çok büyük öneme sahip olan mesleklerle anlatma yolunu seçmişlerdir. Müzik Terimi temasında ortaokul öğrencilerinin öğretmenlerini nota, müzisyen, sol anahtarı gibi müziğin en önemli yapı taşlarından olan müzik terimlerine benzettikleri görülmektedir. Yol Gösterici temasında ortaokul öğrencilerinin öğretmenlerini melek, 1ş1k, su, mum gibi kendilerini aydınlatan ve kendi yollarını bulmalarını sağlayan önemli bir yapıya benzettikleri görülmektedir.

Uysal ve Yorulmaz (2020), tarafından yapılan araştırmada ise ilkokula yeni başlayan öğrencilerin velilerinin sınıf öğretmenini; "bilgi verici ve besleyici”, “seven ve koruyan”, "yetiştirici ve şekillendirici”, "çalışkan ve mücadeleci" ve "yol gösterici ve yönetici” kategorileri altında tanımladıkları görülmektedir. Benzer şekilde bu çalışmada da 
öğrencilerin müzik öğretmenlerini; "yol gösterici” temasının altında "1şık”, “mum”, "kitap”, "bilge" ve "rehber" olarak tanımladıkları belirlenmiştir. Buradan yola çıkarak öğrenci velilerinin ve öğrencilerin öğretmenlere karşı benzer tanımlamalara yer verdikleri söylenebilir.

Çelikten (2006) çalışmasında eğitim sisteminde kullanılan öğretmen metaforlarına ilişkin anne-baba metaforu olumlu bir metafor olarak yer almaktadır. Bu araştırmada da benzer şekilde müzik öğretmenine ilişkin verilmiş metaforlarda anne-baba metaforu yer almaktadır. Dolayısı ile iki çalışmanın benzer olduğu görülmektedir.

Oğuz (2009) tarafından yapılan araştırmada öğretmen adaylarından ortaöğretim alan öğretmenlerini metaforlarla tanımlamaları istenmiştir. Genel olarak ortaöğretim alan öğretmenleri çalışma grubu tarafından "araştırmacı", "rehber”, “ebeveyn”, “mum”, "sanatçı” ve "şef" gibi metaforlarla tanımlanmıştır. Bu araştırmada da çalışma grubu müzik öğretmenlerini benzer metaforlarla ilişkilendirmişlerdir. Bu bağlamda iki çalışma arasında benzerlik göze çarpmaktadır.

Cerit (2008) tarafından yapılan çalışmada öğretmen kavramına ilişkin öğrenci, öğretmen ve yöneticilerin sahip oldukları algılar metaforlar kullanılarak analiz edilmiştir. Çalışmada; "melek", "bilgi kaynağı ve dağıtıcı", "anne-baba”, "arkadaş", "rehber", “danışman” ve "çevresini aydınlatan kişi”” gibi metaforlar göze çarpmaktadır. Bu metaforlar bu çalışmada müzik öğretmenine ilişkin verilen metaforlarla benzerlik gösterdiğinden iki çalışma arasında pozitif yönde bir ilişki olduğu söylenebilir.

Çelik, Çatalbaş ve Tomul (2014) tarafından yapılan ilköğretim öğrencilerinin sınıf öğretmeni algılarının metaforlar aracılığıyla belirlenmesinin amaçlandığı çalışmada öğrenciler iki kategoride 70 metafor üretmişlerdir. Bu metaforlardan çoğunlukla; “aile”, "anne-baba", “ansiklopedi”, “arkadaş", "güneş" ve "melek” bu çalışma ile ortak gözükmektedir. Özellikle "melek” metaforu en çok tekrar eden metafor olarak göze çarpmaktadır. Benzer şekilde bu çalışmada da en çok tekrar edilen metafor "melek" metaforu olmuştur. Buradan yola çıkarak iki çalışmanın benzerliğe sahip olduğu gözlemlenmiştir.

Kalyoncu (2012) tarafindan yapılan çalışmada katılımcıların görsel sanatlar öğretmeni kavramına ilişkin "sanatçı olarak görsel sanatlar öğretmeni” kategorisinde "sanatçı" metaforunun kullanıldığı görülmektedir. Bu çalışmada ise "müzik insanı" kategorisinde yer alan "sanatçı” metaforunun kullanıldığı göze çarpmaktadır. Güzel sanatlar 
eğitimi ana başlığı altında bakıldığında müzik ve görsel sanatlar arasında "sanatçı" metaforunun değişkenlik gösterdiği söylenebilir. Bu durumun iki çalışma grubu arasındaki yaş farkından kaynaklı olduğu düşünülecek olursa, yaş ortalaması arttıkça bireylerin "sanatçı” metaforuna farklı anlamlar yüklemelerinden kaynaklanabileceği düşünülmektedir.

Ünal ve Ünal'ın (2010) çalışmasında "güneş”, “kitap”, “ayna”, “1şık” ve “anne” metaforlarının sıkça kullanıldığı belirlenmiştir. Bu doğrultuda bu çalışmada da müzik öğretmeni bağlamında "güneş", "kitap”, “1ş1k” ve "anne” metaforlarının yoğunlukla kullanıldı̆̆ı görülmektedir. Buradan yola çıkarak bu metaforların öğretmenlik mesleğine ilişkin olumlu yönde sıkça kullanılan metaforlar olduğu söylenebilir.

Y1ldızlı, Erdol, Baştuğ ve Bayram (2018), öğretmen kavramı üzerine yapılan metafor çalışmalarının meta sentezini yaptıkları çalışmada, öğretmene yönelik öğrencilerin ürettiği "bilgisayar, arı, ana-baba, ansiklopedi, güneş, teknoloji, kitap, bilgisayar, anne-baba, kitap, örümcek, 1şık, kitap, bulut" metaforları bilgi kelimesi sabit kalmak kaydıyla ekine; kaynağı/-aktarıcısı /-sahibi/ -sağlayıcı/ -hazinesi/ -öğreten-aydınlatıcı kelimeleri eklenerek isimlendiren temalarda toplanmıştır. Benzer şekilde, çalışmalarda; "güneş, ayna, mum, silgi, anne-baba, melek, arkadaş vb." metaforlar ise "yön veren /yol gösteren" isimli temalarda toplanmıştır. "Anne-baba, melek, doktor, aslan, battaniye, baykuş vb." metaforları koruma kollama güdüsünün öne çıkarıldığı ebeveyn/aile üyesi ve yakın ifadelerle isimlendirilen temalarda yer almıştır. "Gökkuşağı, komik, Cem Yılmaz, melek, eğlenceli oyunu yöneten kişi, ekstra ders, sıcakkanlı" kelimeleriyle üretilen metaforlar mutlu ve eğlenceli olarak isimlendirilen temalar altında toplanmıştır. Ayrıca, "takoz, canavar, acımasız, Azrail, gardiyan, kraliçe arı, ödev veren, kendini beğenmiş, egoist-bencil” gibi olumsuz metaforlar "düzeltilmesi gereken bir varlık, kötü bir insan, baskı yapan emreden kişi, bencil bir insan gibi olumsuz olarak isimlendirilen temaların altında tolanmıştır. Müzik öğretmenini metaforlarla betimlemeye çalışan bu çalışmanın bulguları, yukarıda sözü edilen olumsuz öğretmen metaforlarıyla uyuşmamaktadır. Bu çalışmada müzik öğretmenini olumsuz olarak niteleyen hiçbir metafora rastlanmamıştır.

\section{Öneriler}

Çalışmanın bulguları, metaforların öğrencilerin müzik öğretmenlerine ilişkin kişisel düşüncelerini ortaya çıkarmada yardımcı olabileceğini ve kavrama ilişkin önemli bilgiler sunacağını göstermektedir. Bu çalışmalardan hareketle ve bu çalışma verileri kullanılarak eylem araştırması planlanabilir. Öğretmen adaylarının lisans eğitimleri sırasında bu metaforlar üzerinden değerlendirme yapılarak müzik öğretmenin özellikleri üzerinde 
tartışmalar yürütülür. Öğretmenlerin görev tanımları ve öğretmen yeterlilikleri geliştirlirken metaforlardan yararlanılması önerilebilir.

“Ortaokul Öğrencilerinin Müzik Öğretmenine İlişkin Metaforik Algıları” başlıklı çalışmanın yazım sürecinde bilimsel, etik ve alıntı kurallarına uyulduğunu; toplanan veriler üzerinde herhangi bir tahrifat yapılmadığını, karşılaşılacak tüm etik ihlallerde "Pamukkale Üniversitesi Eğitim Fakültesi Dergisi Yayın Kurulunun” hiçbir sorumluluğunun olmadığını, tüm sorumluluğun Sorumlu Yazara ait olduğunu ve bu çalışmanın herhangi başka bir akademik yayın ortamına değerlendirme için gönderilmemiş olduğunu taahhüt ederim.

Etik Kurul İzin Bilgisi: Bu araştırmanın verileri 2019 yılında toplanmıştır.

Yazar Çıkar Çatışması Bilgisi: Yazarın beyan edeceği bir çıkar çatışması bulunmamaktadir. 


\section{Kaynakça}

Afacan, Ö. (2011). Fen bilgisi öğretmen adaylarının "fen" ve "fen ve teknoloji öğretmeni" kavramlarına yönelik metafor durumları. E-Journal of New World Sciences Academy, 6(1), 1242-1254.

Ahkemoğlu, H. (2011). A study on metaphorical perceptions of efl learners regarding foreign language teacher. Yayınlanmamış yüksek lisans tezi, Çukurova Üniversitesi, Sosyal Bilimler Enstitüsü, Adana.

Ahmethan, N. B., ve Yiğit, V. B. (2018). Müzik öğretmen adaylarının ideal müzik öğretmeni algıları. Mustafa Kemal Üniversitesi Sosyal Bilimler Enstitüsü Dergisi, 15(41), 202-225.

Akbulut, E. (2006). Günümüz müzik eğitimcisi nasıl olmalıdır. Pamukkale Üniversitesi Eğitim Fakültesi Dergisi, 20, 34-41.

Akça Berk, N., Gültekin, F. ve Çençen, N. (2015). Sosyal bilgiler öğretmen adaylarının sosyal bilgiler dersine ve sosyal bilgiler öğretmenine ilişkin metaforları. Ahi Evran Üniversitesi Kırşehir Eğitim Fakültesi Dergisi, 16, 183-199.

Altun, T. ve Camadan, F. (2013). Rehber öğretmenlerin rehber öğretmen (psikolojik danışman) kavramına ilişkin algılarının metafor analizi yoluyla incelenmesi. Kastamonu Ĕ̈itim Dergisi, 21(3), 883-918.

Arslan, M. M. ve Bayrakçı, M. (2006). Metaforik düşünme ve öğrenme yaklaşımının eğitimöğretim açısından incelenmesi. Milli Eğitim, 35(171), 100-108.

Aydın, İ. H. (2006). Bir felsefi metafor "yolda olmak". Din Bilimleri Akademik Araştırma Dergisi, VI, 9-22.

Aydın, İ. S. ve Pehlivan, A. (2010). Türkçe öğretmeni adaylarının “öğretmen” ve "öğrenci” kavramlarına ilişkin kullandıkları metaforlar. Turkish Studies, 5(3), 818-842.

Baltacı, A. (2018). Nitel araştırmalarda örnekleme yöntemleri ve örnek hacmi sorunsalı üzerine kavramsal bir inceleme. Bitlis Eren Üniversitesi Sosyal Bilimler Enstitüsü Dergisi, 37(1), 231-274.

Botha, E. (2009). Why metaphors matters in education. South African Journal of Education, 29(4), 431-444.

Burnard, P. (2016). Professional knowledge in music teacher education. Routledge. 
Büyüköztürk, Ş., Kılıç Çakmak, E., Akgün, Ö. E., Karadeniz, Ş. ve Demirel, F. (2014). Bilimsel araştırma yöntemleri. Ankara: Pegem Yayınları.

Cerit, Y. (2008). Öğretmen kavramı ile ilgili metaforlara ilişkin öğretmen ve yöneticilerin görüşleri. Journal of Turkish Educational Sciences, 6(4), 693-712.

Comte, M. (1988). The arts in australian schools: the past fifty years. Australian Journal of Music Education, 1, 107-115.

Çelik, K., Tomul, E. ve Çatalbaş, G. (2014). İlköğretim kurumu öğrencilerinin "sınıf öğretmeni” kavramına ilişkin metaforik algıları. Akdeniz Eğitim Araştırmaları Dergisi, 6, 1-16.

Çelikkaya, T. ve Seyhan, O. (2017). Sosyal bilgiler öğretmenlerinin ve öğretmen adaylarının evrensel değerlere ilişkin metafor algıları. E-International Journal of Educational Research, 8(3), 65-87.

Çelikten, M. (2006). Kültür ve öğretmen metaforları. Sosyal Bilimler Enstitüsü Dergisi, 21, 269-283.

Çevik Kılıç, D. B. (2016). Müzik öğretmeni adaylarının "öğretmen” kavramına ilişkin metaforları. Kastamonu Ĕ̆itim Dergisi, 25(3), 1099-1118.

Çiçek Sağlam, A. (2008). Müzik öğretmenliği bölümü öğrencilerinin öğretmenlik mesleğine yönelik tutumları. Yüzüncü Yıl Üniversitesi Eğitim Fakültesi Dergisi, 5(1), 59-69.

Dursun, F. (2015). Bilişim teknolojileri öğretmenlerinin kendi branşlarına ilişkin metaforik algılarının incelenmesi. Asya Öğretim Dergisi, 3(1), 66-77.

Eraslan Çapan, B. (2010). Öğretmen adaylarının üstün yetenekli öğrencilere ilişkin metaforik algıları. Uluslararası Sosyal Araştırmalar Dergisi, 3(12), 140-154.

Gedikli, Ö. (2014). Ortaokul 2, 3 ve 4. sınıf öğrencilerinin türkçe öğretmenini algılayışının metaforlar aracılığıyla belirlenmesi. Yayınlanmamış yüksek lisans tezi, Karadeniz Teknik Üniversitesi, Eğitim Bilimleri Enstitüsü, Trabzon.

Giren, S. ve Durak, E. (2015). Okul öncesi öğretmenlerinin oyuncak kavramına ilişkin metaforik algıları. Bartın Üniversitesi Eğitim Fakültesi Dergisi, 4(2), 561-575.

Girgin, D. (2019). Müzik öğretmeni adaylarının çalgı eğitimine yönelik metaforik algıları. Journal of Qualitative Research in Education, 7(1), 161-175. 
Girmen, P. (2007). İlköğretim öğrencilerinin konuşma ve yazma sürecinde metafordan yararlanma durumları. Yayınlanmamış doktora tezi, Anadolu Üniversitesi, Eğitim Bilimleri Enstitüsü, Eskişehir.

Gültekin, M. (2013). İlköğretim öğretmen adaylarının eğitim programı kavramına yükledikleri metaforlar. Education and Science, 38(169), 126-141.

Kalyoncu, N. (2004). Müzik öğretmeni yeterlikleri ve güncel müzik öğretmenliği lisans program1. 1924-2004 Musiki Muallim Mektebinden Günümüze Müzik Öğretmeni Yetiştirme Sempozyumu, 7-10 Nisan, Isparta.

Kalyoncu, R. (2012). Görsel sanatlar öğretmeni adaylarının “öğretmenlik” kavramına ilişkin metaforlar1. Mustafa Kemal Üniversitesi Sosyal Bilimler Enstitüsü Dergisi, 9(20), 471-484.

Karaşahinoğlu, T. (2015). Ortaokullarda beden öğretmenine ilişkin metaforik algılar. Yayınlanmamış yüksek lisans tezi, Ankara Üniversitesi, Sosyal Bilimler Enstitüsü, Ankara.

Kemal, M. (2003). Budhist türk çevresi eserlerinde metafor. Yayınlanmamış doktora tezi, Ankara Üniversitesi, Sosyal Bilimler Enstitüsü, Ankara.

Kılıç, D. B. Ç. (2017). Müzik öğretmeni adaylarının “öğretmen” kavramına ilişkin metaforları. Kastamonu Ĕ̆itim Dergisi, 25(3), 1099-1118.

Koç, E. S. (2014). Sınıf öğretmeni adaylarının öğretmen ve öğretmenlik mesleği kavramlarına ilişkin metaforik algıları. İnönü Üniversitesi Eğitim Fakültesi Dergisi, 9(20), 471-484.

Marshall, H. H. (2001). Metaphor as an instructional tool in encouranging student teacher reflection. Theory into Practice, 29(2), 128-132.

Miles, M. B. ve Huberman, A. M. (1994). Qualitative data analysis: an expanded sourcebook. Thousand Oaks, CA: Sage.

Miller, S. I. (1990). Confirmation and qualitative evidence instances: justifying the use of qualitative research methods. Quality and Quantity, 24, 57-63.

Milli Eğitim Bakanlığı (MEB). (2017). Öğretmenlik mesleği genel yeterlikleri. Öğretmen Yetiştirme ve Geliştirme Genel Müdürlüğ̈̈: Ankara.

Morgan, G. (1986). Images of organization. Newbury Pack, CA: Sage. 
Neuman, L. W. (2014). Social research methods: qualitative and quantitative approaches. Essex: Pearson Education Limited.

Oğuz, A. (2009). Öğretmen adaylarına göre ortaöğretim öğretmenlerini temsil eden metaforlar. Milli Eğitim, 38(182), 36-56.

Öğretmen Yetiştirme ve Geliştirme Genel Müdürlüğü. (2017). Öğretmen mesleği genel yeterlikleri. Milli Eğitim Bakanlı̆̆ı: Ankara.

Özaydın, N. (2019). Müzik öğretmen adaylarının "ses" kavramına ilişkin metaforları. OPUS Uluslararası Toplum Araştırmaları Dergisi, 13(19), 334-358.

Özbaşı, B. Ç. ve Aktekin, S. (2013). Tarih öğretmen adaylarının tarih öğretmenliğine ilişkin inançlarının metafor analizi yoluyla incelenmesi. Eğitimde. Kuram ve Uygulama, 9(3), 211-228.

Patton, M. Q. (2014). Nitel araştırma ve dĕgerlendirme yöntemleri. Pegem Yayımları: Ankara.

Russell Bowie, D., Roche, H., Lawrence, H., ve Marsh, H. (1995). Wow, i can do music! A study of self-concept of student teachers in relation to various subject areas. Australian Association for Research in Music Education (AMEL) Conference, Wollongong.

Saban, A. (2004). Giriş düzeyindeki sınıf öğretmeni adaylarının "öğretmen” kavramına ilişkin ileri sürdükleri metaforlar. Türk Ĕ̆itim Bilimleri Dergisi, 2(2), 131-155.

Sarıtaş, E. ve Çelik, K. (2013). İlkokul öğrencilerinin sınıf kavramına ilişkin metaforik alg1lar1. International Journal of Human Sciences, 10(1), 1185-1201.

Soysal, D. ve Afacan, Ö. (2012). İlköğretim öğrencilerinin “fen ve teknoloji dersi” ve "fen ve teknoloji öğretmeni” kavramlarına yönelik metafor durumları. Mustafa Kemal Üniversitesi Sosyal Bilimler Enstitüsü Dergisi, 9(19), 287-306.

Şahin, B. (2013). Öğretmen adaylarının "matematik öğretmeni”, “matematik” ve "matematik dersi” kavramlarına ilişkin sahip oldukları metaforik algılar. Mersin Üniversitesi Eğitim Fakültesi Dergisi, 9(1), 313-321.

TDK Büyük Türkçe Sözlük. (2020). [Çevrim-içi: https://sozluk.gov.tr/], Erişim tarihi: 20.12.2020. 
Tez, İ. (2016). Ortaokul öğrencilerinin müzik-müzik dersi ve müzik öğretmeni kavramlarına ilişkin algılarının metaforlar aracılığıyla incelenmesi. Yayınlanmamış yüksek lisans tezi, Niğde Üniversitesi, Eğitim Bilimleri Enstitüsü, Niğde.

Tortop, H. S. (2013). Öğretmen adaylarının üniversite hocası hakkındaki metaforları ve bir değerlendirme aracı olarak metafor. Yükseköğretim ve Bilim Dergisi, 3(2), 153-160.

Uçan, A. (2006). Müzik öğretmenliği yeterlikleri. Ulusal Müzik Eğitimi Sempozyumu, 26-28 Nisan, Isparta.

Uysal, H. ve Yorulmaz, A. (2020). İlkokul birinci sınıf öğrenci velilerinin “ilkokul” ve "sınıf öğretmeni” kavramlarına ilişkin metaforik algıları. Uluslararası Alan Eğitimi Dergisi, 6(1), 92-106.

Ünal, A. Ve Ünal, E. (2010). Öğretmen ve öğrencilerin rehber öğretmeni alg1lamalarına ilişkin bir durum çalışması. Uluslararası İnsan Bilimleri Dergisi, 7(2), 919-945.

Wells Yalçın, Ş. (2015). Görsel sanatlar öğretmeni adaylarının öğretmen ve sanatçı algısına ilişkin metafor analizi. Hacettepe Üniversitesi Eğitim Fakültesi Dergisi, 30(3), 160175 .

Yıldırım, A. ve Şimşek, H. (2005). Sosyal bilimlerde nitel araştırma yöntemleri. Ankara: Seçkin Yayıncılık.

Yıldırım, A., Ünal, A. ve Çelik, M. (2011). Öğretmen kavramına ilişkin öğretmen, yönetici ve müfettiş algılarının analizi. Uluslararası İnsan Bilimleri Dergisi, 8(2), 92-109.

Yıldızlı, H., Erdol, T. A., Baştuğ, M. ve Bayram, K. (2018). Türkiye’de öğretmen kavramı üzerine yapılan metafor araştırmalarına yönelik bir meta-sentez çalışması. Eğitim ve Bilim Dergisi, 43(193), 1-43.

Yılmaz, F., Göçen, S. ve Yılmaz, F. (2013). Öğretmen adaylarının öğretmen kavramına ilişkin algıları: bir metaforik çalışma. Mersin Üniversitesi Eğitim Fakültesi Dergisi, 9(1), 151-164.

Yolcu, T. (2020). Nitel araştırma yöntemlerinde metafor-mecaz kullanımı. [Çevrim-içi: https://prezi.com/jjnu5wuxlxzi/nitel-arastrma-yontemlerinde-metafor-mecazkullanm/], Erişim tarihi: 20.08.2020. 


\title{
Secondary School Students' Metaphoric Perceptions of Their Music Teacher
}

\section{Fatıma AKYÜZLÜER *}

- Received: 25.12.2020 • Accepted: 22.01.2021 • Online First: 26.01.2021

\begin{abstract}
This study aims to explore the secondary school 6-7-8. class students' views and opinions about how they see their music teachers' expressions of the world and their effects in the classroom with the help of metaphors. The research is a qualitative study that aims to describe music teachers through metaphors. The world's knowledge and images are impacted by the music teacher and are adapted and adopted by students like those in this study. In this study, we have analyzed these methods. The study was comprised of 1463 students studying in Ağrı, Balıkesir, Batman, Çanakkale, Antalya, Denizli, Diyarbakır, Gaziantep, İstanbul, Kocaeli, and Malatya. By the end of this study, the music teacher guided students through family, music terms, musicians, instruments, and nine learning categories, including nature, sky, and feelings. Interpreting subjects such as the before mentioned and explaining musical terms could be a music teacher's role. The opinion of Junior high school students towards their music teacher is usually positive, so increasing the number of music lessons could increase children's willingness to attend school.
\end{abstract}

Keywords: music teacher, metaphor, secondary school students, simile, analogy

\section{Cited:}

Akyüzlüer, F. (2021). Secondary school students' metaphoric perceptions of their music teacher. Pamukkale University Journal of Education, 53, 60-86.doi:10.9779.pauefd.846801

\footnotetext{
* Doç.Dr., Pamukkale Üniversitesi Eğitim Fakültesi, Doi: 0000-0002-5271-0704, fatmayuz@pau.edu.tr
} 


\section{Introduction}

The number of studies trying to identify and understand the teacher and the teaching profession increases day by day. Researchers conduct research on many subjects ranging from teachers' personality traits to professional characteristics. In the last decade, there has been a marked increase in the importance of imparting description. There have been 13 thesis and 38 articles written on this subject by many researchers, including (Y1ldiz, Erdol, Baştuğ, \& Bayram, 2018).

We can say that many more papers have been written, and many more will be written in the future. According to these studies, teachers in different countries will use different metaphors when describing an idea or object. The ability to use a metaphor is to use different words differently to describe a thing or an idea. In other words, to simplify or paint an image of an idea or object without using language such as like or similar to.

It is the art of using a metaphor to describe a word concept, term, or phenomenon better and differently (Aydın 2006). Metaphors are thought to be the ability to describe more beautifully, is more important and valuable than previously perceived. A metaphor allows us to see and understand the world. A metaphor helps us understand how people perceive and understand the world, actions, objects, and events (Kemal, 2003).

Many studies have been conducted on metaphors in different disciplines since the 1980s. These studies show the effects of metaphors on individuals. Metaphor creates cognitive and affective effects on the individual. The interaction of cognitive and affective processes causes the individual to benefit from metaphors while defining both his / her own emotions and thoughts and giving meaning and understanding to others' emotions and thoughts. In this context, metaphors show both creative thinkings and imagining individuals' styles and their perception of the world and themselves (Girmen, 2007).

Metaphors are extremely important for improving learning. If something new is to be discovered, it must first be able to be imagined. Simultaneously, metaphors build open and clear thoughts and claim intuitive values rather than an ambiguous concept (Çelikkaya \& Seyhan, 2017). Metaphors can be used in various fields of education such as in curriculum development and planning. They are also used in teaching to encourage learning and develop creative thinking. In teacher education, metaphors guide teaching practices and determine teachers' place in modern education (as cited in Vadebocoeur \& Torres. Arslan \& Bayrakc1, 2006). 
The metaphors created by the teacher candidates can explain their opinions, beliefs, and attitudes about their roles in the teaching process and how they see students. Metaphor analysis can help teacher educators to recognize and guide prospective teachers. It should be stated that metaphors can give clues about prospective teachers' source of problems and provide reflective thinking (Marshall, 2001).

Although teaching music - in the broadest sense - is considered a field of practice and a particular discipline that uses professional knowledge and skills in multiple learning contexts, including both formal and informal settings, it is often strictly regulated, scientific but it is not seen as a profession with standardized professional qualifications (Comte 1988; Russell-Bowie et al. 1995; cited in Burnard 2016). It can be said that music teachers have more informal relations with their students than formal ones. Due to the music lesson's nature, they come together with their students for various studies and shows outside of the classroom.

Music teaching is a unique profession. Music teacher education is the process of teaching individuals who are self-directed or directed to this profession in the field of music (Uçan, 2006). The music teacher should have the consciousness and power to eliminate false beliefs and values about art and music in the social and cultural environment in which he lives. The teacher should make the students understand what local, national, and universal music is, eliminate their doubts and raise their consciousness level. The teacher should be aware of the music developments in the local environment, in the country and in the world and share it with the students (Akbulut, 2006).

In addition, a good music teacher should have a piece of good general knowledge, a knowledge of music subject matter and teaching knowledge, and they should also have some personal competencies. The competencies that teachers should gain in the acquisition of a general teaching diploma are professional knowledge, professional skills, values, and attitudes. (MEB, 2017). These competencies can be determinant for pre-service programs. However, it is necessary to know how they perform their profession in the profession, which features stand out, and how students depict them. Studies that evaluate teachers from the perspective of students can make important contributions to both the development of teacher competencies and the improvement of teachers themselves.

There are many studies about metaphors in the field of education in Turkey involving different groups of participants (students, student teachers, teachers, and parents). To give examples; Saban (2004), Aydın and Pehlivan (2010), Çevik Kılıç (2017), teacher; Çelik, 
Çatalbaş, Tomul (2013), primary school teacher; Şahin (2013), a mathematics teacher; Ahkemoğlu (2011) foreign language teacher; Akça Berk, Gültekin, and Çençen, (2015), social studies teacher; Altun and Camadan (2013), counselor; Yalçın Wells (2015), visual arts teacher; Karaşahinoğlu (2015) physical education teacher; Soysal and Afacan (2013), science teacher; Çulha Özbaş and Aktekin (2013), history teacher; Dursun (2015), Information technologies teacher; Giren (2015), preschool teacher; Gedikli (2014), Turkish teacher; Sarıtaş and Çelik (2013) conducted studies on class concept metaphors. Studies on the music teacher and related concepts are limited. Girgin (2019), instrument training; Özaydın (2019), Voice; Ahmethan and Yiğit (2018) music teacher metaphor; Thesis (2016) examined Music, Music Lesson, and Music Teacher metaphors in the same study.

In this study, how music teachers are defined and depicted by middle school students and a professional through metaphors has been examined.

\section{Method}

In many studies, metaphor studies have been based on phenomenology, which is one of the qualitative research methods. However, Patton (2014) states that although the handling of metaphors in the phenomenological method is functional in revealing individuals' experiences through symbols, it should not be reduced to a metaphor analysis of phenomenological studies. For this reason, metaphor analyzes alone may not be sufficient for phenomenological study, but they can form a dimension of the experience (Yildiz, Erdol, Baştuğ, Bayram, 2018). Miller and Fredericks (1988) metaphors state that it can be used within the diversification strategy within the qualitative research tradition (Triangulation) (Yildiz, Erdol, Baştuğ, Bayram, 2018). Metaphor analysis is included in the screening method of qualitative research in some sources, and it is expressed with its name because it is seen as a research methodology in some sources (Yıldız, Erdol, Baştuğ, Bayram, 2018). For the reasons explained, it is accepted that this study was designed in the qualitative research method and the scanning model. The data was analyzed using the content analysis technique.

\section{Participants}

In this study, the Maximum Diversity Sampling method was used to identify large-scale situations and important common patterns to identify differences (Baltac1, 2018; 246). The maximum diversity method aims to discover and define the main themes that cover many differences related to the event or phenomenon studied (Neuman, 2014). The study 
participants study in the 6th, 7th and 8th grades of secondary education in the 2018-2019 academic year. In selecting the study group, the students were asked to have taken music lessons before, and their perception towards the music teacher was formed at a certain level, so 6,7 , and 8 grades were studied. The research was carried out with the participation of 1463 students from Ağrı, Balıkesir, Batman, Çanakkale, Antalya, Denizli, Diyarbakır, Gaziantep, Istanbul, Kocaeli, and Malatya. Of the 1463 students that made up the research group, 452 were 6th grade, 510 were 7 th grade, and 501 were 8 th-grade students. Of the 452 6th grade students, 293 are female, 159 are male, of the 510 7th grade students, 290 are female, 220 are male, and of the 501 8th grade students, 298 are female, and 203 are male.

\section{Data Collection Procedure}

One form was used to determine the metaphors the study group produced for a music teacher's concept. The data were collected in the students' classroom environments by the music teachers, where the researcher gave training in applying the form. My music teacher from the study group is ........ like this; because ......... "they were asked to complete the sentence. The forms explain what and why the participants compared the music teacher with their handwriting in their main data source.

\section{Data Analysis}

In this research, the analysis of the data was made by using the content analysis technique. Content analysis is a systematic technique that is separated into upper and lower categories in which neutral inferences are made from the message presented as a text with coding within the framework of certain rules (Büyüköztürk, Çakmak, \& Akgün, et al., 2009). The main purpose of content analysis is to reach the concepts and relationships and explain the collected data. The collected data are first conceptualized and organized according to these concepts, and themes are determined (Yıldırım \& Şimşek, 2005). The category creation studies were carried out in listing, screening, category development, creating themes, specifying the data frequencies, and evaluation. Research data was first made into a list based on the metaphors produced and their reasons. Then, data forms that were thought to be unrelated to metaphor were excluded from the study. One hundred forty-seven of the researcher's 1610 forms were removed, and 1463 forms were included in the research data. The data included in the research were coded according to the concepts. As a result of these encodings, nine main themes and many metaphors were determined. The nine main themes determined; Family, living things, nature, emotion, instrument, sky, a person of music, terms of music, and guidance. 


\section{Validity and Reliability}

The study's validity was attempted to create a meaningful whole of the themes created while analyzing the data and explaining the research process in detail. In order to increase the reliability of the research, all of the findings are given directly without any comments. At the same time, another expert's opinion was received to increase reliability. Accordingly, after the metaphors related to the research were divided into themes, another field expert was asked to place the metaphors in the given categories. The study calculated the effect of consensus and dissent on reliability using the reliability formula (Reliability $=$ Consensus $\mathrm{x}$ 100 / Consensus + Disagreement) of Miles and Huberman (1994). As a result, it was determined that there is $83 \%$ of consensus. As a result of all these procedures, it can be said that the study is valid and reliable.

\section{Results}

As a result of the collected data analysis, the "music teacher" has been expressed in nine themes and themes with numerous metaphors, as shown below. The themes obtained from the research are presented in Figure 1 briefly, and the themes and metaphors are interpreted in tables-figure 1. Music Teacher Themes When the results regarding the themes are evaluated in general, the common themes seen in many teacher metaphor studies are also seen in this study. New themes specific to the profession of music teaching are also obtained. A meta-analysis study examines teacher metaphors (Yildiz, Erdol, Baştuğ, \& Bayram, 2018). In this study, some themes were formed specifically for the work of music teachers. The music teacher's themes are mainly composed of metaphors with a heavy emotional load and can reflect the work's emotional dimension. Table 1 shows the metaphors produced in the "family" theme created from the students' answers about what / who their music teachers are similar to and the frequencies related to these metaphors. 


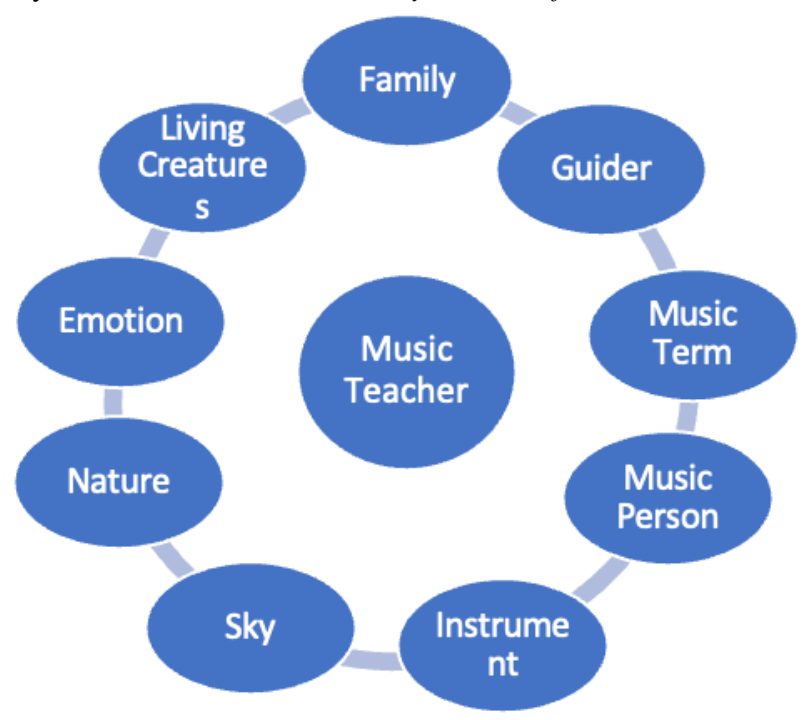

Figure 1. Music Teacher Themes

When the results regarding the themes are evaluated in general, the common themes seen in many teacher metaphor studies are also seen in this study. New themes specific to the profession of music teaching are also obtained. It is seen that teachers try to be explained with similar themes in metaphor analyses conducted with very different groups. A metaanalysis study examines teacher metaphors (Yildiz, Erdol, Baştuğ, \& Bayram, 2018); The metaphors produced for teachers emphasize that it is gathered under three themes called information provider, shaper-formative, and a good person. In this study, some themes were formed specifically for the work of music teachers. The music teacher's themes are mainly composed of metaphors with a heavy emotional load and can reflect the work's emotional dimension.

Table 1 shows the metaphors produced in the "family" theme created from the students' answers about what their music teachers look like and the frequencies related to these metaphors. 


\begin{tabular}{llr}
\hline Theme & Generated Metaphors & $\mathrm{f}$ \\
\hline Mother & 35 \\
& Father & 21 \\
& Family & \\
& Elder brother and elder sister & 9 \\
Family & Mother and father & 7 \\
& Parent & 6 \\
& Child & \\
& Relative, home, sister & Once \\
\hline
\end{tabular}

When the metaphors and explanations in this category were examined, it was seen that the student's perspective of the music teacher was formed with their approach to and behavior towards their students rather than their professional characteristics or roles. They explained this relationship with their expressions of affection, warmth, sincerity, and protecting their students, and they were described with metaphors such as my mother, father, brother, and sister. Participants justified their reasons for the metaphor formed and expressed on the form in this theme; "He acts like a mother, he loves us very much, protects us, loves us, teaches us to play the flute, does everything, gives knowledge, behaves well, compassionate, makes.... he loves music, turns the school into a home, is compassionate, teaches new things, guides us, takes care of us. "Considering that the students are middle school students, it can be said that they want to see their teachers as close as a member of their family. Especially, it is seen that metaphors are mostly collected in expressions of mother-father, brother-sister. This situation can be interpreted as students seeking a close relationship with their teachers.

Table 2 shows the subcategories formed in the "living things" theme created from the students' answers regarding their music teacher's perceptions and the frequencies related to these categories. 


\begin{tabular}{|c|c|c|}
\hline Theme & Generated Metaphors & $\mathrm{f}$ \\
\hline & Nightingale & 36 \\
\hline & Bird & 31 \\
\hline & Bee & 4 \\
\hline & Cat & 4 \\
\hline & Butterfly & 4 \\
\hline & Fly & 4 \\
\hline \multirow{7}{*}{$\begin{array}{l}\text { Living } \\
\text { Creatures }\end{array}$} & Lion & 3 \\
\hline & Wolf & 3 \\
\hline & Parrot & 3 \\
\hline & Swa & 2 \\
\hline & Panda & 2 \\
\hline & Rabbit & 2 \\
\hline & Horse, insect, grasshopper, çekirge, ant, budgie & Once \\
\hline
\end{tabular}

When the metaphors in the living creatures category and the explanations of these metaphors were examined, it was seen that the students, when considering the music teacher and forming their perceptions, made a correlation between the teachers approach to their students in terms of their professional characteristics and roles and the creatures in nature that they had heard about. Students express their feelings, "His voice is very beautiful, he impresses everyone with his voice, just like a nightingale, free and happy like a bird, graceful with art; They justified it as" swan-like. "With these simulations, it was observed that the students admired and directly reflected the free souls of individuals engaged in art. It is noteworthy that the metaphor of "nightingale and bird," which stands out in this theme, is associated with beautiful vocal creatures in our culture. 
Table 3 shows the subcategories formed in the "Nature" theme from the students' answers regarding their music teacher's perceptions and the frequencies related to these categories.

Table 3. Nature Theme Subcategories and Frequencies

\begin{tabular}{|c|c|c|}
\hline Theme & Generated Metaphors & $\mathrm{f}$ \\
\hline & Flower & 131 \\
\hline & Rose & 38 \\
\hline & Tree & 15 \\
\hline & Daisy & 13 \\
\hline & Wind & 8 \\
\hline & Honey & 3 \\
\hline & Forest & 3 \\
\hline & Spring & 2 \\
\hline Nature & Plant & 2 \\
\hline & Apple & 2 \\
\hline & Lake & 2 \\
\hline & $\begin{array}{l}\text { Sunflower, heaven, strawberry, thorn, thorn rose, thornless rose, } \\
\text { nature, the inner voice of nature, snowdrop, tulip, fruit tree, } \\
\text { pomegranate, river, ocean, orange, leaf, fun, life, sugar, joy, love } \\
\text { flower, fairy, can cotton, friendly, cotton candy, paint, energetic, } \\
\text { excitement, tranquility, joy, chocolate, food, hero, amusement park, } \\
\text { clown, love quotes, sea, tongue, cupboard, ice cream, emotion, emoji, } \\
\text { breeze, movie, filter, smoothie, indulgence, pearl, human, fairy } \\
\text { godmother, cream kadayif, Turkish delight, machine, tangerine, } \\
\text { delicate piece, delicate cloud, breath, cake-cream, diamond, a patience }\end{array}$ & Once \\
\hline
\end{tabular}


stone, serotonin, sound waves, favorite food, hot air, magic song, stove, unfading rose, waterfall, cute, table, wood, field, stone, freshly opened rose, poison

In the theme of nature, metaphors for music teachers such as flowers, roses, trees, daisies, wind, forest, etc., were used. It can be said through their metaphors that students see music as a part of nature. Just like other beings in nature, there is an understanding that music nurtures and develops our souls. The students described their teachers as follows "He is like a flower, he blooms like a flower, he makes the flowers dance, the branches do not break off, you find beauty the deeper you go, it does not prick even though it has a thorn, it is the most beautiful creature, he refreshes us with his knowledge like a breeze, he collects us in his shade, he is like a beautiful flower, the blooms again with every piece of music. Everyone loves a rose. Everyone embarrasses nature. The students are his leaves. He bewitches us with his color and honor. He produces new flowers. The "flower and rose" metaphor that stands out, blooms in spring, leaves fragrant scents, the forest is a huge place and makes different sounds. This theme can be associated with beauty and love. It can be said that music teachers' ability to create such an atmosphere is desirable for student-teacher bonding.

Table 4 shows the subcategories formed in the "Emotion" theme formed by the students' responses about what their music teachers look like and the frequencies in these categories.

Table 4. Emotion Theme Subcategories and Frequencies

\begin{tabular}{llr} 
Theme & Generated Metaphors & $\mathrm{f}$ \\
\hline Entertainment & 20 \\
& Life & 20 \\
& Sugar & 19 \\
Emotion & & 14
\end{tabular}

$\begin{array}{ll}\text { Love flower } & 14\end{array}$

$\begin{array}{ll}\text { Fairy } & 7\end{array}$ 
$\begin{array}{lr}\text { Cotton } & 5\end{array}$

$\begin{array}{lr}\text { Friend } & 4\end{array}$

Cotton Candy 4

$\begin{array}{ll}\text { Paint } & 3\end{array}$

Energetic 3

$\begin{array}{ll}\text { Excitement } & 3\end{array}$

Serenity 3

Joy 3

$\begin{array}{ll}\text { Chocolate } & 2\end{array}$

Food 2

Hero 2

$\begin{array}{ll}\text { Funfair } & 2\end{array}$

Clown 2

Love words, sea, tongue, cupboard, ice cream, emotion, emoji, breeze, movie, filter, smoothie, indulgence, pearl, human, fairy godmother, kadayif with cream, Turkish delight, machine, tangerine, delicate piece, delicate cloud, breath, cake-cream, diamond, a patience stone, Once serotonin, sound waves, favorite food, hot air, magic song, stove, nonfading rose, waterfall, cute, table, wooden, field, stone, freshly opened rose, poison

Teachers' metaphors of entertainment, mission, candy, joy, love flower, fairy, soul, and cotton come to the fore in the theme of emotion. Students justify these metaphors as "a tool that enlivens the student, gives vitality and happiness with his voice, entertains, makes the lesson happy and enjoyable, nourishes the soul, connects to life, gives hope and make them 
social." One of these lessons aims that music appeals to our emotions, and students have fun in their lessons and connect to life. In this respect, it can be said that music teachers have realized the aims of the lessons.

Table 5 shows the subcategories formed in the "Instrument" theme formed from the students' answers regarding what their music looks like and the frequencies in these categories.

Table 5. Instrument Theme Subcategories and Frequencies

\begin{tabular}{llr}
\hline Theme & Generated Metaphors & $\mathrm{f}$ \\
\hline & Instrument & 24 \\
& Instrument / piano & 11 \\
& Instrument / guitar & 8 \\
& Instrument / flute & 6 \\
Instrument & Instrument / violin & 4 \\
& Instrument / binding & 3 \\
& Instrument / melodica & 2 \\
& Instrument / drumset , Instrument / drum, Instrument / saz & Once \\
\hline
\end{tabular}

In the instrument theme, some simulations were made between the musical instruments teachers used with the teachers. In the justifications related to this, he speaks like an instrument, plays everything, connects the notes, helps us to play, his voice comes from the strings, he fascinates the person with his voice, when his strings are combined, a whole is formed, his proximity with the strings depends on his students, takes them to other worlds, harmonious together, explain the feelings in music., he plays the piano, has all the notes in his voice, it sounds beautiful ".

Table 6 shows the subcategories formed in the "Sky" theme created from the students' answers regarding their perception of their music teachers and the frequencies related to these categories. 


\begin{tabular}{llr}
\hline Theme & Generated Metaphors & $\mathrm{f}$ \\
\hline Sun & 88 \\
Moon & 23 \\
Star & 21 \\
Rain & 7 \\
Cloud & 6 \\
Sky & 4 \\
Rainbow & 3 \\
Daytime, spring, black hole & Once \\
\hline
\end{tabular}

Students chose to describe their teachers with sky objects such as shining like the sun, moon, and stars in the sky theme. From these simulations, it can be said that such celestial bodies shine and reflect, and a correlation that music teachers are elements of a shining profession that enlightens the students. The universality of music and the idea of infinity created in emotions can be seen with the sky theme. The expressions of the students regarding this theme: 'He illuminates, he shines, he illuminates our way, he shines, he illuminates our future, he is hot like a cloud, hot like the sun, we are happy when we see him, we remember our dreams, he is eternal, he scatters like a star, he illuminates our world, he shines like the sun, he illuminates us with his happiness. He, he enlightens us with his light, makes our future shine".

Table 7 shows the subcategories formed in the "Music Person" theme created from the students' answers regarding their music teachers' perceptions and the frequencies in these categories. 


\begin{tabular}{llr} 
Theme & Generated Metaphors & $\mathrm{f}$ \\
\hline & Artist & 74 \\
& Singer & 56 \\
& Doctor & 4 \\
& Choir Conductor & 4 \\
Pusic & & 4 \\
& Conductor & 3 \\
& Comedian & 3 \\
& Painter & \\
& $\begin{array}{l}\text { Barış Manço, Farmer, Shepherd, Nurse, Sculptor, Construction Worker, } \\
\end{array}$ & Once
\end{tabular}

In this theme, teachers are mostly compared to artists and singers. This is expected for music teachers. Also, in this theme, students likened their teachers to some professions and named them. From the simulations here, the teachers' healing, entertaining, emotional, productive, and master aspects are emphasized. The students' expressions regarding this theme are "they heal with music, shape us, build our draw with notes, read, become artists, learn art, teach art, give peace, give morale, is a musician.". In this theme, students drew attention to the performing aspect of music teaching. This situation stems from the fact that the music lesson is practical.

Table 8 shows the subcategories formed in the "Music Term" theme formed from the answers given by students regarding their perceptions of their music teachers and the frequencies in these categories 


\begin{tabular}{|c|c|c|}
\hline Theme & Generated Metaphors & $\mathrm{f}$ \\
\hline & Note & 79 \\
\hline & Musician & 15 \\
\hline & Treble clef & 10 \\
\hline & Melody & 6 \\
\hline Music & Sound & 5 \\
\hline Term & Music Book & 2 \\
\hline & Music Box & 2 \\
\hline & Rhythm & 2 \\
\hline & $\begin{array}{l}\text { Composition, music mother, music store, music dictionary, note queen, } \\
\text { musical note tree, orchestra, pop star, Porte, harmony, folk song }\end{array}$ & $\begin{array}{l}1 \text { 'er } \\
\text { kez }\end{array}$ \\
\hline
\end{tabular}

In this theme, teachers are mostly likened to the notes, musicians, and the Treble Clef. In this theme, students associated their teachers with music terms. Students' expressions related to this theme " knows the notes, teaches... to play the flute, has different thoughts like each different note, symbolizes music, music consists of notes, music notes are beautiful like a teacher, they are beautiful like notes, they show notes, they give sound to the notes, they know the notes very well, he makes us feel the music, he is one of the notes, a friend of the notes, similar to the notes, making notes while singing, like lyrics, rising and falling, keeping us all together, animating every sound, he is at the beginning of everything, he is at the beginning of every note ".

Table 9 shows the subcategories formed in the "Guiding" theme created from the students' answers regarding their perceptions of music teachers and the frequencies in these categories. 
Table 9. Guider Subcategories and Frequencies

\begin{tabular}{|c|c|c|}
\hline Theme & Generated Metaphors & $\mathrm{f}$ \\
\hline & Angel & 123 \\
\hline & Light & 30 \\
\hline & That & 25 \\
\hline & Candle & 15 \\
\hline & Book & 14 \\
\hline & Wise & 9 \\
\hline & Friend & 8 \\
\hline & Queen & 8 \\
\hline & Key & 6 \\
\hline & world & 5 \\
\hline & Pen & 5 \\
\hline \multirow[t]{8}{*}{ Guider } & Princess & 5 \\
\hline & Lantern & 4 \\
\hline & Guide & 4 \\
\hline & Spirit Feeder & 4 \\
\hline & Oil lamp & 3 \\
\hline & Psychologist & 3 \\
\hline & $\begin{array}{l}\text { Mind Cube, Fire, Mirror, Flag, Diamond, Door, Library, } \\
\text { Leader, Tutorial, Superhero, Director }\end{array}$ & $\begin{array}{r}2 \\
\text { times }\end{array}$ \\
\hline & $\begin{array}{l}\text { Gold, encyclopedia, hunter, crown, brain, locksmith, wave, } \\
\text { waves, drip, Einstein, conqueror, sprouted seed, philosopher, } \\
\text { fireworks, inspiration, source, pole star, lamp, torch, counsel, } \\
\text { free bird, freedom, freedom fairy, glitter, bright, bright star, } \\
\text { shining sun, prince, professor, compass, clock, travel, sports } \\
\text { coach, train, flying balloon, flying bird, master, writer, foliage, } \\
\text { yoga teacher, administrator }\end{array}$ & Once \\
\hline
\end{tabular}


In this theme, teachers are mostly likened to angels, light, water, and candles. In this theme, students saw their teachers as guides. In this theme, their teachers teach the students as was shown by their comments such as "They are knowledgeable, always teach, open the doors to other worlds, are aware, they are the doors to the future, they open difficult doors, you find remedies when you tell them your problems, they want the best for us, act like an angel, protect and love us, see everything, smile if you smile, empower us for dark days, there is a wave in his voice, he reads our minds, he knows what we do not know, the waves in the sea make music, make a puddle, the secret pours into the music, he knows everything about music, it makes us feel, the music and the notes conquer, everything I dream of, lights our way into the future, sheds light on the darkness, sacrifices himself to teach us, gives us light, you may not like the outside but it is very enjoyable inside, it has different talents and skills, it is understood with words, the more you read the more you want to read, the most beautiful instructor, dire cts the lesson, teaches the music, directs the army, guides, has all the information, does not discriminate, you relax like an angel in class, makes it beautiful, is like life itself, connects to life, is kind-hearted, thinks of our well-being, has wings, has the face of an angel, compassionate, you can trust him, special, has wings, is an angel of music, melts when illuminating, shines light on those around him, leads behind the locked door, the door to the future, the princess of voices, understands the emotion in our soul, solves problems, directs, understands what we feel, connects to life, takes us to where it flows, is very pure and clear, you relax, explains music like water, has wings, makes impressive presentations, controls the flow of music ". It can be said that students emphasize the leadership role of their teachers with these simulations.

\section{Discussion}

Numerous metaphors in 9 themes were produced to determine what middle school students compared their teachers. Secondary school students have not produced any negative metaphors about music teachers. The interest in the music lesson and the music teacher was

frequently emphasized throughout the study. Numerous metaphors have been produced in themes named "Family," "Guiding," "Music Term," "Music Person," "Instrument," "Sky," "Nature," "Emotion," and "Living Beings."

In the study conducted by Tez (2016) on the concept of a music teacher, metaphors were collected under the categories of "loving, reassuring and protecting," "artist," "source of information," "admired." It can be said that the categories in the study of the thesis are similar to this study. Barışeri Ahmethan and Yiğit (2018), in their studies where the music 
teacher candidates determined their ideal music teacher through metaphors, "loving and supportive teacher," "knowledge transfer teacher," "teacher who reveals and directs talents," "remarkable teacher," "It was observed that they were perceived as" fun teacher, "therapist teacher, "highly motivated teacher, "authoritarian teacher "and" just teacher. "

If we evaluate the metaphors of 9 themes produced in this study in general, the following results are obtained. In the family theme, it can be said that middle school students see their teachers as close as someone from the family, such as parents or older sisters. In the theme of emotion, it is seen that middle school students adorn themselves with positive emotions such as fun, life, sugar, and joy. In the creatures' theme, it is seen that middle school students liken their teachers to creatures with beautiful sounds such as nightingales and birds. In nature's theme, they described middle school students' teachers as one of our most vital functions that allow them to breathe lifelike flowers, roses, and trees. In the sky theme, they likened middle school students' teachers to objects that illuminate the sky like the sun, the moon, and the stars, that guide and emit light. In the theme of instruments, they described middle school students' teachers with instruments, piano, guitar sound, and timbre that make people feel pleasant. In the theme of People of Music, secondary school students chose to explain their teachers with professions such as artists, singers, which are of great importance in music life. In the Music Term theme, it is seen that middle school students liken their teachers to musical terms, which are among the most important building blocks of music, such as note, musician, treble clef. In the Guiding theme, it is seen that middle school students liken their teachers to important structures such as angles, light, water, candles that enlighten them and enable them to find their way.

In the study conducted by Uysal and Yorulmaz (2020), the classroom teacher of the parents of the students who have just started primary school; It is seen that they define them under the categories of "informative and nurturing," "loving and protecting," "nurturing and shaping," "hardworking and challenging" and "guiding and managing." Similarly, in this study, students' music teachers; it has been determined that they use "light," "candle," "book," "wise," and "guide" under the "guiding" theme. Based on this, it can be said that parents of students and students use similar definitions towards teachers.

In the study of Çelikten (2006), the parents' metaphor regarding the teacher metaphors used in the education system is included as a positive metaphor. Similarly, in this study, the mother-father's metaphors are included in the metaphors regarding the music teacher. Therefore, it is seen that the two studies are similar. 
In the study conducted by Oğuz (2009), pre-service teachers were asked to describe their secondary education teachers with metaphors. In general, secondary education field teachers were defined by the study group with metaphors such as "researcher", "guide", "parent", "candle", "artist" and "chef". In this study, the study group associated music teachers with similar metaphors. In this context, there is a similarity between the two studies.

In the study conducted by Cerit (2008), teachers and administrators' perceptions regarding the teacher's concept were analyzed using metaphors. In the study; Metaphors such as "angel", "information source and distributor", "parent", "friend", "guide", "counselor" and "person who enlightens his environment" stand out. Since these metaphors are similar to those given about the music teacher in this study, it can be said that there is a positive relationship between the two studies.

In the study conducted by Çelik, Çatalbaş, and Tomul (2014), which aims to determine the classroom teacher perceptions of primary school students through metaphors, students produced 70 metaphors in two main categories. Most of these metaphors; "Family", "parents", "encyclopedia", "friend", "sun" and "angel" seem to be common with this study. Especially, the "angel" metaphor stands out as the most repetitive one. Similarly, in this study, the most frequently repeated metaphor was the "angel" metaphor. Based on this, it has been observed that the two studies have similarities.

In the study conducted by Kalyoncu (2012), it is seen that the metaphor of "artist" is used in the category of "teacher of visual arts as an artist" regarding the concept of visual arts teacher of the participants. In this study, it is striking that the metaphor of "artist" in the "music person" category is used. When considered under the main title of fine arts education, it can be said that the metaphor of "artist" varies between music and visual arts. Considering that this situation is due to the age difference between the two study groups, it is thought that as the average age increases, individuals attribute different meanings to the "artist" metaphor.

In Ünal and Ünal's (2010) study, it was determined that the metaphors "sun," "book," "mirror," "light," and "mother" were frequently used. Accordingly, in this study, it is seen that the metaphors of "sun," "book," "light," and "mother" are used intensely in the context of a music teacher. Based on this, it can be said that these metaphors are frequently used positively about the teaching profession. 
Yıldız, Erdol, Baştuğ, and Bayram (2018), in their study on metaphor studies on the concept of teachers, metaphors that students produce for "teacher" mostly; information source/information source-transmitter / knowledge provider/knowledge treasure/knowledge teacher-enlightener (computer, bee, parent, encyclopedia, sun, technology, book, computer, parent, book, spider, light, book, cloud, directing / guiding / guiding-guiding-influencer (sun, mirror, candle, eraser, parent, angel, friend, etc.), parent / affectionate / family member/reassuring / watcher-guardian-related-helper-good / loving / protecting supporting person/helping (parent, angel, doctor, lion, blanket, owl, etc.), happy and funny (rainbow, funny, Cem Y1lmaz, angel, funny it is seen that the themes are produced such as the person leading the game, the extra lesson, the warm-blooded. It is noteworthy that there are negative themes, such as human (self-righteous, egoistic, selfish). Their opinions do not match with the negatively described teacher metaphors.

\section{Suggestions}

The study's findings show that metaphors can help reveal students' personal thoughts about music teachers and provide important information about the concept. Action research can be planned based on these studies and using these study data. During the undergraduate education of teacher candidates, discussions are made on the music teacher's characteristics by evaluating these metaphors. It can be suggested to use metaphors while developing teachers' job descriptions and teacher competencies.

In the writing process of the study titled "Metaphoric Perceptions of Secondary School Students Regarding Music Teachers", it was observed that scientific, ethical, and quotation rules were followed; I undertake that no falsification has been made on the collected data, that the Editorial Board of the Journal of the Faculty of Education of Pamukkale University has no responsibility for all ethical violations, that all responsibility belongs to the Responsible Author, and that this study has not been sent to any other academic publication media for evaluation.

Ethical Approval: The data of this research were collected in 2019.

Conflict Interest: The author declares that there is no conflict of interest. 


\section{References}

Afacan, Ö. (2011). Fen bilgisi öğretmen adaylarının "fen" ve "fen ve teknoloji öğretmeni" kavramlarına yönelik metafor durumları. E-Journal of New World Sciences Academy, 6(1), 1242-1254.

Ahmethan, N. B., ve Yiğit, V. B. (2017). Müzik öğretmen adaylarının ideal müzik öğretmeni algıları. Mustafa Kemal Üniversitesi Sosyal Bilimler Enstitüsü Dergisi, 15(41), 202-225.

Akbulut, E. (2006). Günümüz müzik eğitimcisi nasıl olmalıdır. Pamukkale Üniversitesi Ĕ̈itim Fakültesi Dergisi, 20, 34-41.

Arslan, M. M. ve Bayrakçı, M. (2006). Metaforik düşünme ve öğrenme yaklaşımının eğitimöğretim açısından incelenmesi. Milli Eğitim, 35(171), 100-108.

Aydın, İ. H. (2006). Bir felsefi metafor "yolda olmak". Din Bilimleri Akademik Araştırma Dergisi, VI, 9-22.

Baltacı, A. (2018). Nitel araştırmalarda örnekleme yöntemleri ve örnek hacmi sorunsalı üzerine kavramsal bir inceleme. Bitlis Eren Üniversitesi Sosyal Bilimler Enstitüsü Dergisi, 37(1), 231-274.

Botha, E. (2009). Why metaphors matters in education. South African Journal of Education, 29(4), 431-444.

Burnard, P. (2016). Professional knowledge in music teacher education. Routledge.

Büyüköztürk, Ş., Kılıç Çakmak, E., Akgün, Ö. E., Karadeniz, Ş. ve Demirel, F. (2014). Bilimsel araştırma yöntemleri. Ankara: Pegem Yayınları.

Cerit, Y. (2008). Öğretmen kavramı ile ilgili metaforlara ilişkin öğretmen ve yöneticilerin görüşleri. Journal of Turkish Educational Sciences, 6(4), 693-712.

Comte, M. (1988). The arts in australian schools: the past fifty years. Australian Journal of Music Education, 1, 107-115.

Çelik, K., Tomul, E. ve Çatalbaş, G. (2014). İlköğretim kurumu öğrencilerinin "sınıf öğretmeni” kavramına ilişkin metaforik algıları. Akdeniz Eğitim Araştırmaları Dergisi, 6, 1-16. 
Çelikkaya, T. ve Seyhan, O. (2017). Sosyal bilgiler öğretmenlerinin ve öğretmen adaylarının evrensel değerlere ilişkin metafor algıları. E-International Journal of Educational Research, 8(3), 65-87.

Çelikten, M. (2006). Kültür ve öğretmen metaforları. Sosyal Bilimler Enstitüsü Dergisi, 21, 269-283.

Çevik Kılıç, D. B. (2016). Müzik öğretmeni adaylarının "öğretmen” kavramına ilişkin metaforları. Kastamonu Ĕ̆itim Dergisi, 25(3), 1099-1118.

Çiçek Sağlam, A. (2008). Müzik öğretmenliği bölümü öğrencilerinin öğretmenlik mesleğine yönelik tutumları. Yüzüncü Yıl Üniversitesi Eğitim Fakültesi Dergisi, 5(1), 59-69.

Eraslan Çapan, B. (2010). Öğretmen adaylarının üstün yetenekli öğrencilere ilişkin metaforik algıları. Uluslararası Sosyal Araştırmalar Dergisi, 3(12), 140-154.

Girgin, D. (2019). Müzik öğretmeni adaylarının çalg1 eğitimine yönelik metaforik algıları. Journal of Qualitative Research in Education, 7(1), 161-175.

Girmen, P. (2007). İlköğretim öğrencilerinin konuşma ve yazma sürecinde metafordan yararlanma durumları. Yayınlanmamış doktora tezi, Anadolu Üniversitesi, Eğitim Bilimleri Enstitüsü, Eskişehir.

Gültekin, M. (2013). İlköğretim öğretmen adaylarının eğitim programı kavramına yükledikleri metaforlar. Education and Science, 38(169), 126-141.

Kalyoncu, N. (2004). Müzik öğretmeni yeterlikleri ve güncel müzik öğretmenliği lisans programı. 1924-2004 Musiki Muallim Mektebinden Günümüze Müzik Öğretmeni Yetiştirme Sempozyumu, 7-10 Nisan, Isparta.

Kalyoncu, R. (2012). Görsel sanatlar öğretmeni adaylarının “öğretmenlik” kavramına ilişkin metaforları. Mustafa Kemal Üniversitesi Sosyal Bilimler Enstitüsü Dergisi, 9(20), 471-484.

Kemal, M. (2003). Budhist türk çevresi eserlerinde metafor. Yayınlanmamış doktora tezi, Ankara Üniversitesi, Sosyal Bilimler Enstitüsü, Ankara.

Kılıç, D. B. Ç. (2017). Müzik öğretmeni adaylarının “öğretmen” kavramına ilişkin metaforları. Kastamonu Ĕ̆itim Dergisi, 25(3), 1099-1118. 
Koç, E. S. (2014). Sınıf öğretmeni adaylarının öğretmen ve öğretmenlik mesleği kavramlarına ilişkin metaforik algıları. İnönü Üniversitesi Eğitim Fakültesi Dergisi, 9(20), 471-484.

Marshall, H. H. (2001). Metaphor as an instructional tool in encouranging student teacher reflection. Theory into Practice, 29(2), 128-132.

Miles, M. B. ve Huberman, A. M. (1994). Qualitative data analysis: an expanded sourcebook. Thousand Oaks, CA: Sage.

Morgan, G. (1986). Images of organization. Newbury Pack, CA: Sage.

Neuman, L. W. (2014). Social research methods: qualitative and quantitative approaches. Essex: Pearson Education Limited.

Oğuz, A. (2009). Öğretmen adaylarına göre ortaöğretim öğretmenlerini temsil eden metaforlar. Milli Ĕ̈itim, 38(182), 36-56.

Öğretmen Yetiştirme ve Geliştirme Genel Müdürlüğü. (2017). Öğretmen mesleği genel yeterlikleri. Milli Eğitim Bakanlığı: Ankara.

Özaydın, N. (2019). Müzik öğretmen adaylarının "ses" kavramına ilişkin metaforları. OPUS Uluslararası Toplum Araştırmaları Dergisi, 13(19), 334-358.

Özbaşı, B. Ç. ve Aktekin, S. (2013). Tarih öğretmen adaylarının tarih öğretmenliğine ilişkin inançlarının metafor analizi yoluyla incelenmesi. Eğitimde. Kuram ve Uygulama, 9(3), 211-228.

Palmquist, R. A. (2001). Cognitive style and users' metaphors for the web: an exploratory study. The Journal of Academic Librarianship, 27(1), 24-32.

Russell Bowie, D., Roche, H., Lawrence, H., ve Marsh, H. (1995). Wow, i can do music! A study of self-concept of student teachers in relation to various subject areas. Australian Association for Research in Music Education (AMEL) Conference, Wollongong.

Saban, A. (2004). Giriş düzeyindeki sınıf öğretmeni adaylarının "öğretmen” kavramına ilişkin ileri sürdükleri metaforlar. Türk Ĕgitim Bilimleri Dergisi, 2(2), 131-155.

Sarıtaş, E. ve Çelik, K. (2013). İlkokul öğrencilerinin sınıf kavramına ilişkin metaforik alg1lar1. International Journal of Human Sciences, 10(1), 1185-1201. 
TDK Büyük Türkçe Sözlük. (2020). [Çevrim-içi: https://sozluk.gov.tr/], Erişim tarihi: 20.12.2020.

Tez, İ. (2016). Ortaokul öğrencilerinin müzik-müzik dersi ve müzik öğretmeni kavramlarına ilişkin algılarının metaforlar aracılığılyla incelenmesi. Yayınlanmamış yüksek lisans tezi, Niğde Üniversitesi, Eğitim Bilimleri Enstitüsü, Niğde.

Tortop, H. S. (2013). Öğretmen adaylarının üniversite hocası hakkındaki metaforları ve bir değerlendirme aracı olarak metafor. Yükseköğretim ve Bilim Dergisi, 3(2), 153-160.

Uçan, A. (2006). Müzik öğretmenliği yeterlikleri. Ulusal Müzik Eğitimi Sempozyumu, 26-28 Nisan, Isparta.

Ünal, A. Ve Ünal, E. (2010). Öğretmen ve öğrencilerin rehber öğretmeni algılamalarına ilişkin bir durum çalışması. Uluslararası İnsan Bilimleri Dergisi, 7(2), 919-945.

Wells Yalçın, Ş. (2015). Görsel sanatlar öğretmeni adaylarının öğretmen ve sanatçı algısına ilişkin metafor analizi.. Hacettepe Üniversitesi Ĕgitim Fakültesi Dergisi, 30(3), 160175.

Yıldırım, A. ve Şimşek, H. (2005). Sosyal bilimlerde nitel araştırma yöntemleri. Ankara: Seçkin Yayıncılık.

Yıldırım, A., Ünal, A. ve Çelik, M. (2011). Öğretmen kavramına ilişkin öğretmen, yönetici ve müfettiş algılarının analizi. Uluslararası İnsan Bilimleri Dergisi, 8(2), 92-109.

Yıldızlı, H., Erdol, T. A., Baştuğ, M. ve Bayram, K. (2018). Türkiye'de öğretmen kavramı üzerine yapılan metafor araştırmalarına yönelik bir meta-sentez çalışması. Eğitim ve Bilim Dergisi, 43(193), 1-43.

Yılmaz, F., Göçen, S. ve Yılmaz, F. (2013). Öğretmen adaylarının öğretmen kavramına ilişkin algıları: bir metaforik çalışma. Mersin Üniversitesi Eğitim Fakültesi Dergisi, 9(1), 151-164.

Yolcu, T. (2020). Nitel araştırma yöntemlerinde metafor-mecaz kullanımı. [Çevrim-içi: https://prezi.com/jjnu5wuxlxzi/nitel-arastrma-yontemlerinde-metafor-mecazkullanm/], Erişim tarihi: 20.08.2020. 